\title{
ARCHIMÈDE N4
}

1 DOSSIER THÉMATIQUE 1 : NOMMER LES « ORIENTAUX » DANS L'ANTIQUITÉ

DOSSIER THÉMATIQUE 2 : PRYTANÉE ET REGIA

87 Michel HUMM

Introduction. Prytanée et Regia : demeures « royales » ou sanctuaires civiques ? Athènes, Rome et la « médiation » étrusque

94 Patrick MARCHETTI

Les prytanées d'Athènes

110 Dominique BRIQUEL

Les monuments de type Regia dans le monde étrusque, Murlo et Acquarossa

129 Michel HUMM

La Regia, le rex sacrorum et la Res publica

155 ACTUALITÉ DE LA RECHERCHE : DYNAMIQUES HUMAINES ANCIENNES

216 VARIA

236 LA CHRONIQUE D'ARCHIMÈDE 


\title{
LA REGIA, LE REX SACRORUM ET LA RES PUBLICA
}

\author{
Michel HUMM \\ Professeur d'histoire romaine \\ Université de Strasbourg \\ UMR 7044 Archimède \\ michel.humm@unistra.fr
}

L'évolution architecturale de la Regia, entre la fin de la «Royauté » et le début de la République, ne permet pas de confirmer l'apparition concomitante du rex sacrorum et du régime politique républicain. Ce prêtre occupait à l'origine une place prééminente dans l'ordo sacerdotum et ne verra son rôle être éclipsé par le pontifex maximus qu'au cours du Iv ${ }^{\text {e }}$ siècle av. J.-C. Ses fonctions religieuses étaient exercées dans la Regia, à la curia Calabra et au Comitium. Le rex sacrorum républicain ne peut être que le prolongement d'un « roi-prêtre » (rex) qui exerçait ses fonctions aux côtés des chefs politiques

MotS-CLÉS

Calator, comitia calata

flamines, institutions,

Minotaure, pontifes, pontifex maximus,

Regia,

République,

roi (rex),

roi des sacrifices (rex sacrorum), Royauté,

topographie romaine, triomphe. et militaires de la cité, peut-être dès la fin du VII $^{\mathrm{e}}$ siècle. La sclérose architecturale de la Regia, à partir du début de la période républicaine, indique à la fois la fin des bouleversements politiques de l'époque archaïque et le début d'un lent déclin de la fonction du « roi-prêtre ».
The architectural evolution of the Regia between the end of the « Kingship » and the beginning of the Republic doesn't allow to confirm the concomitant appearance of the rex sacrorum and of the republican political régime. This priest was at the origin holding a prevailing position in the ordo sacerdotum and it's only during the $\mathrm{IV}^{\text {th }}$ century BC that his role was outshined by the pontifex maximus' one. His religious functions were accomplished in the Regia, at the curia Calabra and at the Comitium. The republican rex sacrorum can only be the prolongation of a « kingpriest » (rex) who was doing his functions next to the political and military chiefs of the city, maybe since the end of the $\mathrm{VII}^{\text {th }}$ century BC. The architectural sclerosis of the Regia starting at the beginning of the republican period reveals both the end of the political changings of the archaic age and the beginning of the slow decline of the function of the « king-priest ».

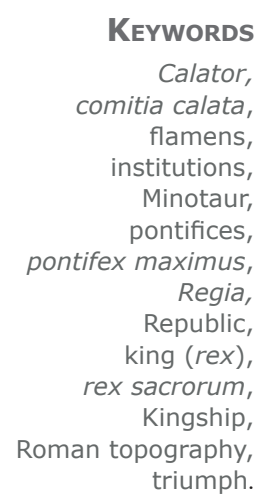


Sous la République romaine, et encore tout au long du Principat, existait au cœur de Rome, en plein Forum, une « maison royale » (domus regia) précisément appelée Regia. Fréquemment évoqué par les sources littéraires, ce bâtiment a été reconnu dans la construction de forme trapézoïdale qui s'étend devant le temple d'Antonin et Faustine, à l'arrière du temple de Jules César divinisé, le long de la via Sacra, non loin du temple rond de Vesta (fig. 1) [1]. L'identification de ces ruines avec la Regia dont parlent les sources littéraires a été définitivement confirmée par la découverte, lors des fouilles de G. Boni en 1899, sous le pavement républicain, d'une coupe en bucchero du dernier quart du $\mathrm{VI}^{\mathrm{e}}$ siècle av. J.-C. portant I'inscription REX (fig. 2) [2]. Ce témoignage épigraphique peut être complété par la découverte de l'inscription $\operatorname{REGI}(A)$ figurant sur un fragment de travertin (d'époque républicaine) retrouvé dans la citerne du monument et provenant probablement de la margelle du puits qui se trouvait au-dessus de la structure souterraine (fig. 3) [3].

Malgré sa place centrale au Forum, la construction n'était pas bien grande et présente un plan assez curieux, constitué de trois pièces rectangulaires disposées en enfilade sur son côté sud, et d'une cour intérieure de forme triangulaire disposant d'une ouverture à l'est et bordée par des portiques sur

[1] Voir en dernier lieu : Scotr 1999a (avec bibliographie antérieure); CARNABUCI 2012.

[2] CIL I² 2830 ; GJeRSTAD 1960, p. 300 et fig. 199, 4 ; GuARDUCCI 1972 ; WACHTER 1987, p. 96-96 ; M. Cristofani, dans CRIStofani 1990, p. 22-23 ( $\left.n^{\circ} 1.9\right)$; voir aussi infra n. 51. Sur les fouilles de G. Boni, voir le manuscrit de ses comptes rendus de fouilles dans CARNABUCI 2012, p. 27-59.

[3] CIL VI $36842=C I L I^{2} 1007$ (p. 840, 966) =ILLRP 1264 ; voir Carnabuci 2012, p. 79-80 et fig. 42.

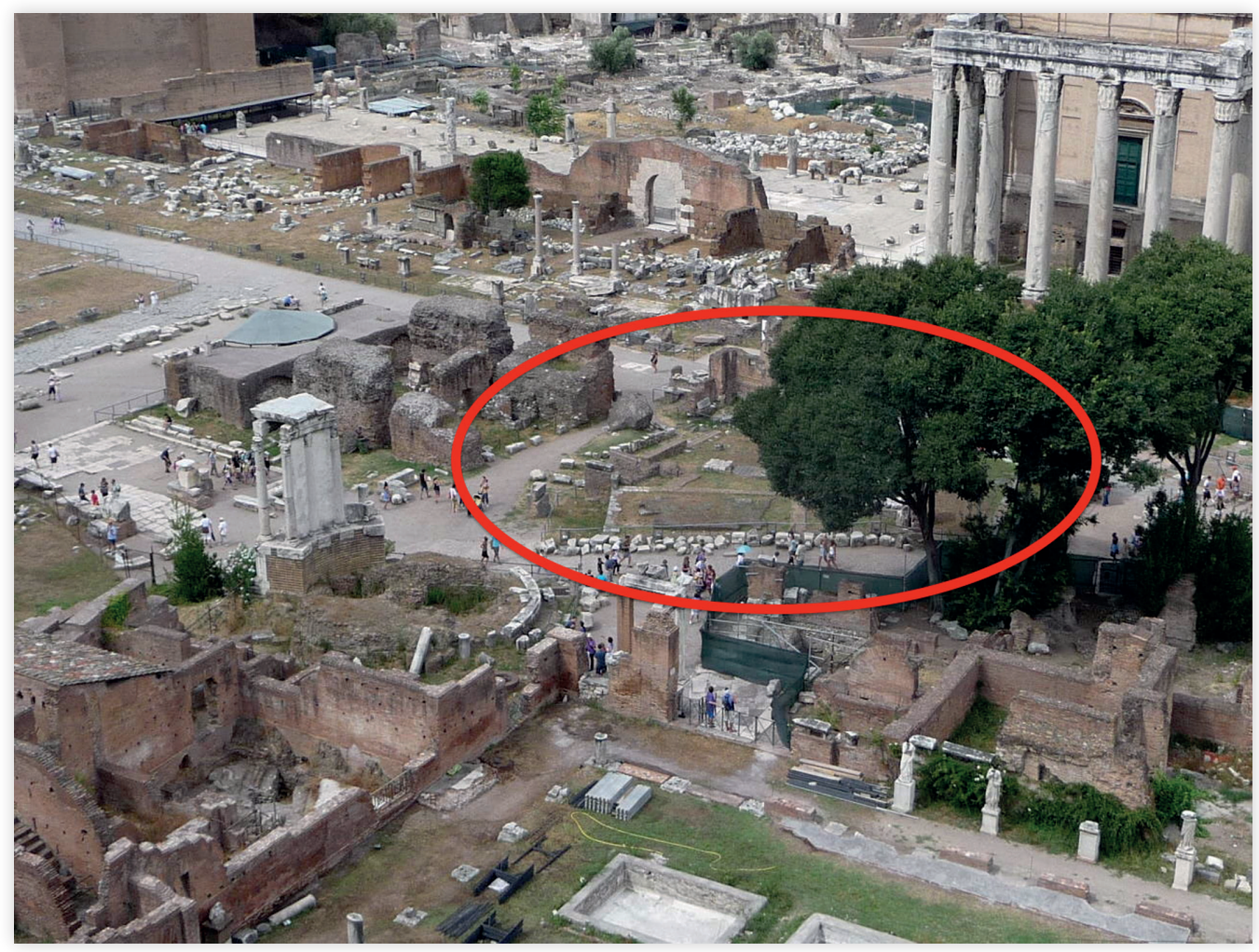

Figure 1

Le secteur de la Regia (cercle rouge) au Forum romain. Cliché : M. Humm. 


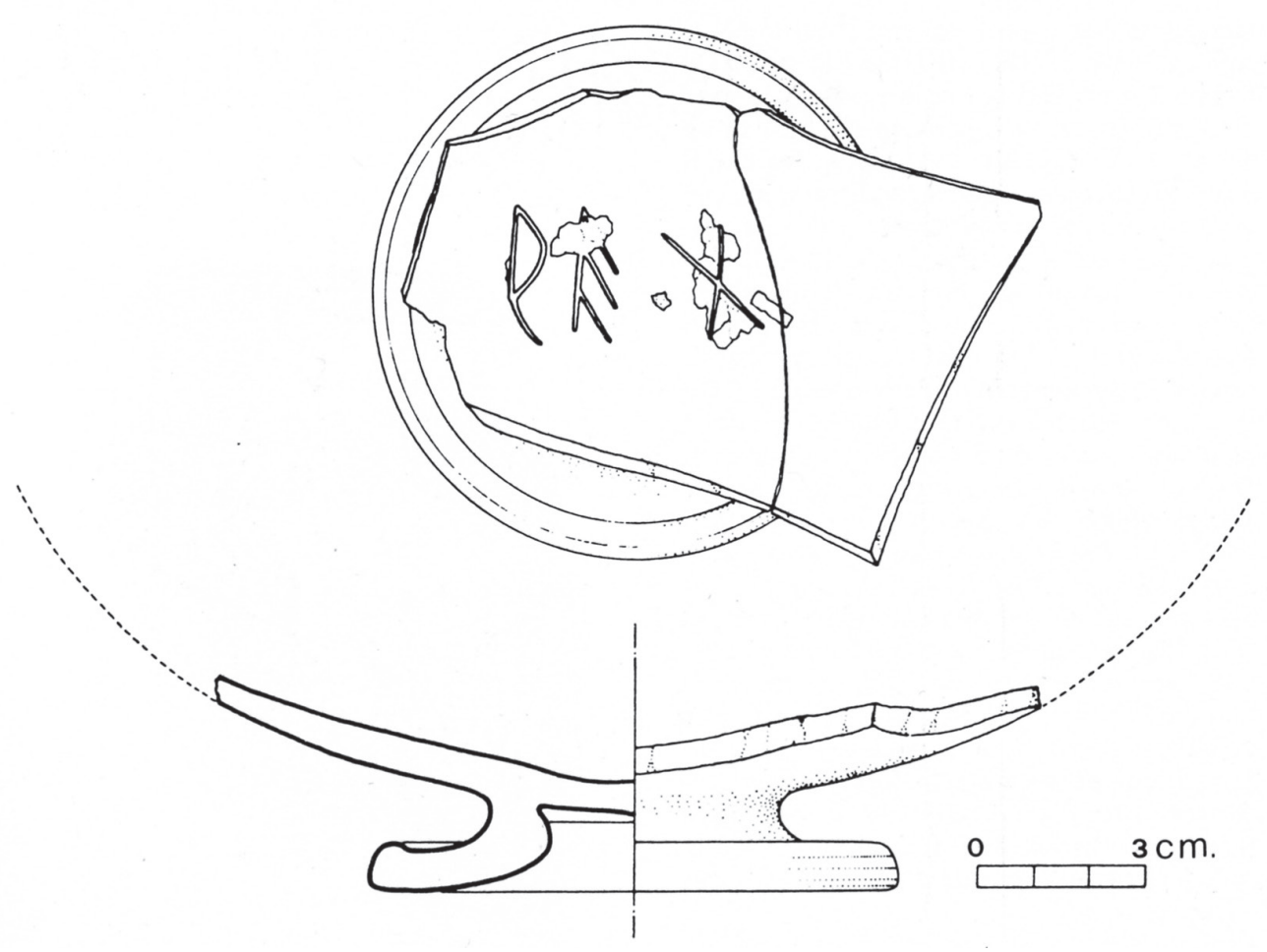

$<$ Figure 2

Coupe en bucchero avec l'inscription REX (CRISTOFANI 1990, p. 23, fig. 1.9, (c) éditions « L'Erma » di Bretschneider, Rome).

$\checkmark$ Figure 3

Inscription REGI(A) sur un fragment de travertin (CARnabuci 2012, p. 80 , fig. 42 , (C) éditions Quasar, Rome).

deux côtés (fig. 4). Mais surtout, dans un État (res publica) qui cultivait sciemment la « détestation de la royauté » (odium regni), on peut se demander à quoi pouvait bien servir une telle « maison royale» (Regia) placée au cœur de la cité. Les sources littéraires de la fin de la République ou du Principat expliquent en fait que le bâtiment était ainsi appelé parce que c'était l'emplacement où avait jadis habité le roi (rex) [4], ou plus précisément que c'était le lieu où officiait le prêtre, membre du collège pontifical, qui était appelé « roi des sacrifices » ou plutôt « roi des rites sacrés » (rex sacrorum ou rex sacrificulus) [5]. Certaines sources donnaient également le nom de Regia à la demeure du pontifex maximus sur le Forum [6] ; mais le nom de Regia qui est parfois donné par les sources à cette résidence

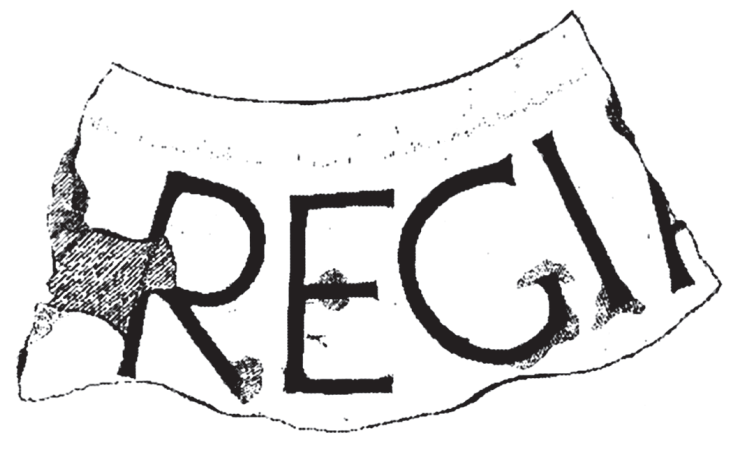

de fonction (domus publica) du grand pontife doit venir du fait qu'elle avait été primitivement occupée par le rex sacrorum [7]. L'existence de ce prêtre appelé « roi » (rex) était justifiée par la nécessité qu'il y aurait eu à maintenir un certain nombre de
[4] Paul Diacre, Extraits tirés de Festus, p. 347 Lindsay, s.v. Regia : « La Regia est la maison où habite le roi (rex) ». Servius, Commentaire sur l'Énéide de Virgile, II, 57 : « La maison du flamine est appelée Flaminia, comme la maison du roi (rex) est appelée Regia ».

[5] Festus, p. 346-348 L. : <Regia> quod in fanum a pon<tifice $>$....................... tant, quod in ea sa <cra fiunt quaedam a rege sol>ita usurpari (« Regia : on appelle ainsi un édifice où les prêtres convoqués par le pontife se réunissent comme dans un temple (fanum), parce qu'on y accomplit des sacrifices qui étaient d'ordinaire pratiqués par le roi <des sacrifices> »). Cf. Ovide, Fastes, VI, 263-264 (infra n. 73) ; Plutarque, Numa, 14, 1-2 (infra n. 73) ; Solin, I, 21 (infra n. 73) ; Dion Cassius, LIV, 27, 3 (infra n. 6).

[6] Dion Cassius, LIV , 27, 2-3 : « Lorsque, à la mort de
Lépidus, il [sc. Auguste] fut élu grand pontife, et que le sénat, pour ce motif, voulut lui décerner des honneurs, il protesta qu'il n'en accepterait aucun, et, comme on insistait, il se leva et sortit de la salle des délibérations. Ces décrets ne furent donc pas ratifiés, et, au lieu de recevoir de l'État une maison pour y demeurer, il ouvrit au public une partie de la sienne, attendu que le grand pontife était obligé de demeurer dans un édifice public. De plus, il fit don aux Vestales de la maison du roi des rites sacrés, parce qu'elle touchait à leurs demeures. » (trad. d'après E. Gros, Paris, 1865). Servius, Commentaire sur l'Énéide de Virgile, VIII, 363 : « en effet, la maison dans laquelle habite le pontife est appelée Regia, parce que le rex sacrificulus a I'habitude d'y habiter ». Cf. aussi Pline le Jeune, Lettres, IV, 11, 6.

[7] Momigliano 1969 , p. 395 ; CAStagnoli 1993, p. 383-385; voir infra fig. 6 (domus regis). 


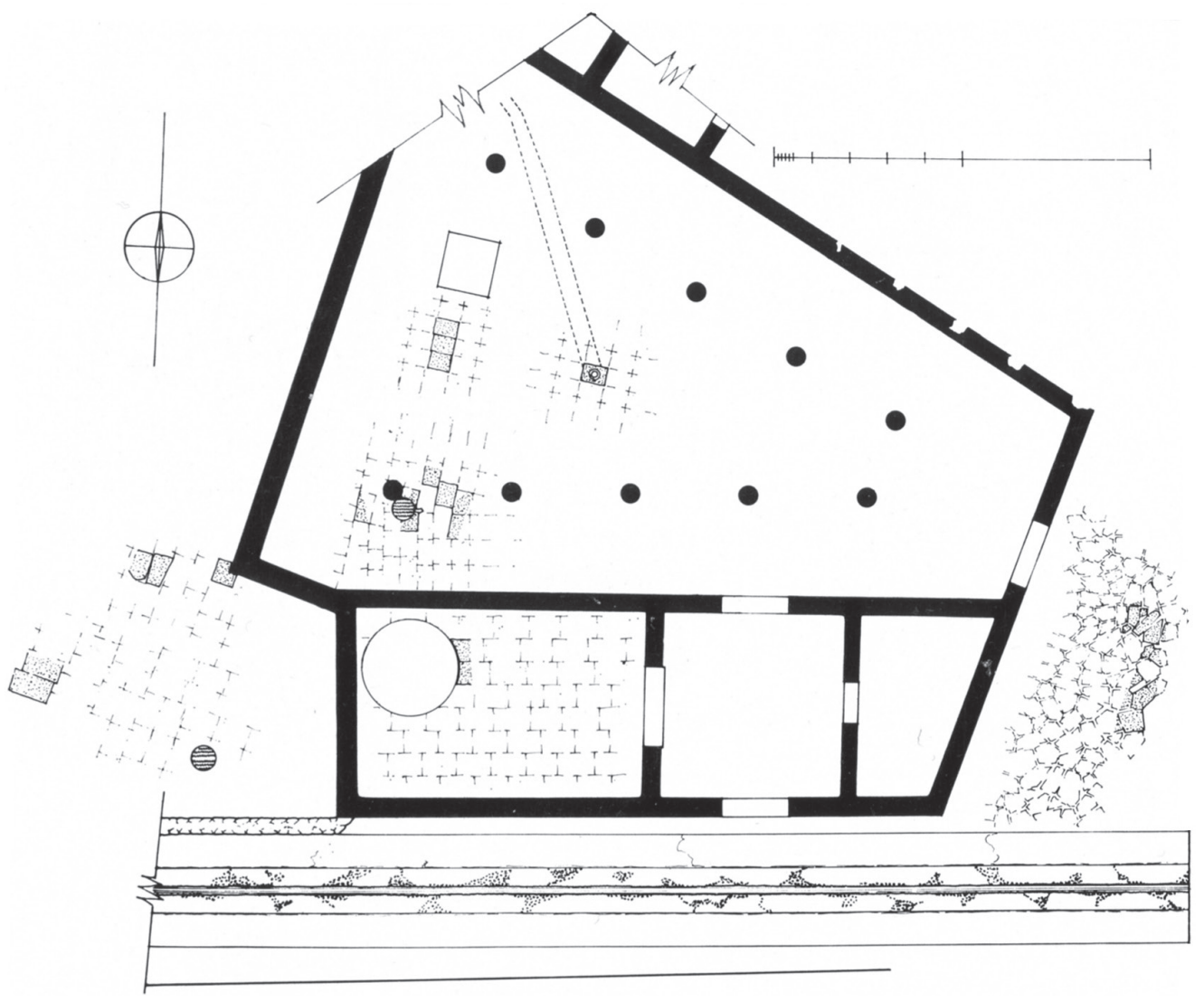

Figure 4

La cinquième phase de la Regia

(CoARELLI 1986,

p. 60 , fig. 16 [d'après BRown 1967], (C) éditions Quasar, Rome).

sacrifices et de rites religieux auparavant effectués par le vrai roi, après le départ de Tarquin le Superbe [8] : le « roi des rites sacrés » serait donc un roi de substitution créé par la République romaine, et évoque l'archonte athénien appelé


de la royauté qui passait pour la plus ancienne d'Athènes [9] ; le rex sacrorum serait même apparu dès la première année du nouveau régime, en 509 av. J.-C., afin que les cultes pratiqués à la Regia ne souffrissent d'aucune interruption. Parmi ces cultes, les sources littéraires indiquent ceux de Jupiter et de Junon, auxquels la regina sacrorum offrait un sacrifice respectivement aux nondines (un bélier) et aux calendes (une truie ou une agnelle), celui de Janus, « dieu de janvier et de tous les commencements »(G. Dumézil), auquel le rex sacrifiait un bélier à l'agonium du 9 janvier (première fête de l'année), et enfin ceux de Mars et d'Ops Consiva, qui auraient chacun disposé d'un sacrarium au sein de la Regia et qui symbolisaient respectivement la protection guerrière et l'abondance agricole que la cité (ou son roi) demandait à ses dieux [10]. On peut dès lors se demander si la fonction de ce monument était celle, politique, d'un palais (royal), ou celle d'un sanctuaire religieux.
[8] Tite-Live, II, 1, 9 ; 2, 1-2 ; Denys d'Halicarnasse, Antiquités Romaines, IV, 74, 4 ; V 11,4 ; Plutarque, Questions Romaines, 63 (Mor., 279 C-D) ; Festus, p. 422 L., s.v. Sacrificulus rex (cf. Paul Diacre, Extraits tirés de Festus, p. 423 L., s.v. Sacrificulus rex). Cf. Rosenberg 1914b; BendLIN 2001, col. 938.

[9] Denys d'Halicarnasse, Antiquités Romaines, IV, 74, 4 : «Afin que le nom ancestral de la puissance royale

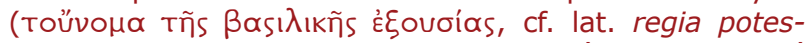
tas), qui existe chez nous et qui est arrivé dans cette cité avec des auspices favorables manifestant l'approbation des dieux, puisse être préservé pour les cérémonies religieuses, désignons donc toujours un roi des rites sacrés

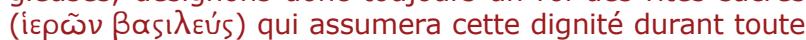
sa vie, en étant totalement exempté de toute charge militaire et politique, et qui sera chargé de cette unique fonction, comme le roi <à Athènes> (
[Reiske] $\beta \propto$ sı $\lambda \varepsilon u ́ s)$, à savoir la direction des sacrifices, et rien d'autre ». Cf. Pseudo-Aristote, Constitution d'Athènes, III, 2 ; LVI, 1; LVII, 1-4. Voir CARLIER 1984, p. 325-372.

[10] Sacrifice à Jupiter : Macrobe, Saturnales, I, 16, 30 ; à Junon : Ovide, Fastes, I, 55 ; Macrobe, Saturnales, I, 15, 19 ; à Janus : Ovide, Fastes, I, 318 ; Varron, La langue latine, VI, 12 ; sacrarium Martis : Servius, Commentaire sur l'Énéide de Virgile, VII, 603 ; VIII, 3 ; sacrarium Opis Consivae : Varron, La langue latine, VI, 21 ; Festus, p. 202 L., s.v. Opima spolia ; p. 292 L., s.v. Praefericulum. Pour TOReLli 1997, p. 113, les sacraria de Mars et d'Ops symboliseraient, dans la partie « sacralisée » de l'ancienne demeure du roi, « lo spazio maschile e quello feminile (...), ipostasi della capacità generativa e dei compiti sociali dei due sessi, quello della guerra dell'uomo e quello della tesaurizzazione della donna »; voir aussi MeNICHETTI 1994, p. 99-100. 
D'autre part, peut-on réellement établir un lien entre l'évolution architecturale de la Regia et l'évolution institutionnelle de l'État romain, notamment au moment de la création de la Res publica en 509 ? La documentation archéologique aujourd'hui disponible permet-elle de confirmer la vision traditionnelle qui continue à associer, dans nos manuels d'histoire romaine, l'instauration de la République avec la fin du règne des « rois », et celle-ci avec la création, en leur lieu et place, d'un prêtre appelé rex sacrorum [11] ?

\section{LA REGIA, RÉSIDENCE « ROYALE » OU SANCTUAIRE RELIGIEUX?}

Les fouilles américaines dirigées par F. E. Brown en 1964-1965 ont, un moment, semblé confirmer à la fois cette chronologie et cette interprétation institutionnelle [12]. Les fouilles ont montré que la Regia a connu une histoire assez compliquée : les ruines actuellement visibles remontent à la reconstruction du bâtiment effectuée ex manubiis par $\mathrm{Cn}$. Domitius Calvinus en 36 av. J.-C. [13]. Cette reconstruction reproduisait pour l'essentiel la forme adoptée par la Regia à la fin $\mathrm{du}_{\mathrm{VI}}^{\mathrm{e}}$ siècle av. J.-C. (fig. 4), avec ses trois pièces alignées sur le côté méridional de la cour centrale et orientées sur un axe est-ouest, le long du vicus Vestae [14] (il s'agit en réalité de deux chambres qui ouvrent sur un vestibule central qui, seul, donne accès à la cour). Mais les fouilles ont également permis d'établir l'existence, au même emplacement, de plusieurs phases de construction antérieures (fig. 5), dont la plus ancienne remonte au dernier quart du viI ${ }^{\mathrm{e}}$ siècle (phase précédée, aux $\mathrm{VIII}^{\mathrm{e}}$ et $\mathrm{VII}^{\mathrm{e}}$ siècles, par un groupe de huttes ou de cabanes périodiquement reconstruites après incendies et qui semblent avoir été délibérément séparées de l'habitat protohistorique installé sur le Palatin et la Vélia [15]).

[11] Cf. Momigliano 1969, p. 395-402 ; Linke 1995, p. $149-150$; BRIQUel 2000, p. 160.

[12] Brown 1967. Ces fouilles avaient été précédées par une étude détaillée des vestiges architecturaux encore visibles en 1933 : Brown 1935 ; I'histoire des fouilles sur le site de la Regia est présentée par CARNABUCI 2012, p. 13-26.

[13] Dion Cassius, XLVIII, 42, 4-6 ; Pline I'Ancien, Histoire naturelle, XXXIV, 48; CIL VI $1301=$ ILS 42 ; cf. Münzer 1905 ; Carandini 2010, p. 71-74. Voir Scott 1999a.

[14] Coarelli 1999c ; Carnabuci 2012, p. 105.

[15] Brown 1974-1975, p. 19 ; Carandini 1997,

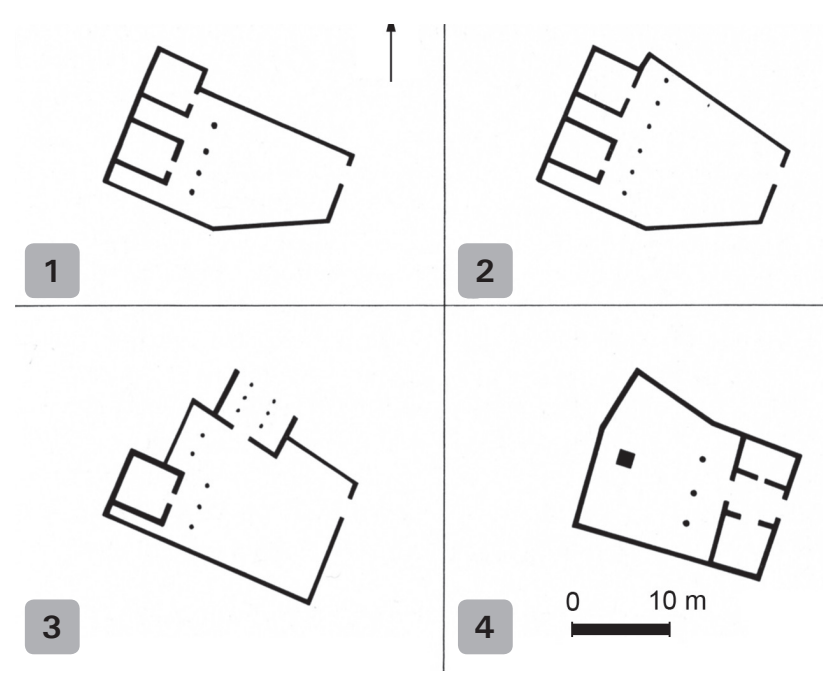

Figure 5

Les quatre premières phases architecturales de la Regia (COARELLI 1986, p. 59, fig. 15 [d'après BRown 1974-1975], (c) éditions Quasar, Rome).

Les différentes phases de construction de la Regia sont marquées par des destructions et des incendies qui précèdent à chaque fois la phase suivante [16]. Les deux chambres, identifiées avec les sacraria attribués respectivement à Mars et à Ops Consiva (voir infra), se retrouvent à chacune des cinq phases de construction [17], mais leur emplacement et leur orientation changent d'une phase à l'autre: d'abord situées sur le côté occidental du monument (phases I et II, fin $\mathrm{VII}^{\mathrm{e}}$ et début $\mathrm{VI}^{\mathrm{e}}$ siècles), puis simultanément dans l'angle sud-ouest et sur le côté septentrional (phase III, vers 570 - 530), elles sont ensuite situées sur le côté oriental (phase IV, vers $530 / 525-510 / 500$ ) et enfin sur le côté méridional (phase $\mathrm{V}$, fin $\mathrm{VI}^{\mathrm{e}}$ siècle). C'est à la $3^{\mathrm{e}}$ phase qu'appartient la fameuse décoration architectonique en terre cuite représentant une frise de lionnes ou de panthères, de « minotaures » (infra fig. 8), d'autruches ou de grues, ainsi que des bucrânes, et la $4^{\mathrm{e}}$ phase coïncide avec l'installation d'un premier autel

p. 511-512 et fig. XVII-XVIII ; SCOT 1999a, p. 190-191. [16] Présentation détaillée des différentes phases de construction de la Regia par : BRown 1974-1975, p. 21-33 ; Coarelli 1986, p. 59-61 ; Holloway 1994, p. 62-67; SCOTT 1999a, p. 190-192 ; LOSEHAND 2007, p. 12-27; Carnabuci 2012, p. 21-25.

[17] La réalité ou la consistance de la deuxième phase de construction semble aujourd'hui remise en cause par certains savants (C. Ampolo), ce qui ne change d'ailleurs pas grand-chose sur l'évolution générale de la structure et son interprétation historique ; par commodité, et pour éviter tout risque de confusion, nous allons conserver la numérotation traditionnelle des cinq phases. 
sur le côté ouest de la cour, dont l'emplacement demeurera ensuite inchangé malgré les nouveaux changements dans I'orientation des bâtiments (cet autel est identifié avec celui où des sacrifices étaient périodiquement offerts à Janus, Jupiter et Junon par le rex et la regina sacrorum, le flamen Dialis et la flaminica, le pontifex maximus et les Vestales, et où I'on versait le sang de l'October equus [18]). Les différentes séquences chronologiques sont datées grâce à la céramique grecque importée ainsi qu'à la production locale d'impasto et de bucchero retrouvées sur place.

En 1966, dans les « Entretiens sur l'Antiquité classique » de la Fondation Hardt consacrés aux Origines de la République romaine, Frank E. Brown voulait voir dans les différentes phases antérieures du monument l'évolution d'un complexe cultuel $\mathrm{qu}^{\prime} \mathrm{il}$ assimilait à un temple [19]. Sa destruction par un incendie à la fin $\mathrm{du} \mathrm{VI}^{\mathrm{e}}$ siècle aurait amené son remplacement par un nouveau type de construction : celui de la Regia proprement dite, dont la forme et le plan ne changeront plus jusqu'à la fin de I'Antiquité (supra fig. 4). Ce constat l'a alors amené à voir dans la modification architecturale du monument à la fin $\mathrm{du} \mathrm{VI}^{\mathrm{e}}$ siècle la preuve archéologique de la création du rex sacrorum, et donc du passage de la Royauté à la République. De son côté, F. Coarelli a lui aussi voulu voir la trace matérielle du changement de régime politique à Rome à la fin $d u v^{e}{ }^{e}$ siècle dans l'évolution architecturale de la Regia et dans la sclérose (sclerotizzazione) architecturale qui a suivi l'adoption de sa cinquième phase de construction [20]. Pour l'archéologue italien, la Regia archaïque, l'aedes Vestae, la domus Vestalium (ou atrium Vestae) et le quartier d'habitation de la maison du roi (domus regis) auraient été intimement liés entre eux par leurs fonctions religieuses : l'ensemble aurait constitué le palais royal primitif sur le Forum, ou plus précisément «le noyau le plus ancien d'une habitation royale » [21] ; celle-ci aurait été associée à différents cultes domestiques, notamment celui du foyer (Vesta) et ceux du garde-manger (les Lares et les Pénates), mais aussi au culte de Mars, qui symbolisait le rôle de guerrier joué par le roi, ainsi qu'au culte d'Ops Consiva, une divinité de l'abondance agricole, apparentée à Consus (dieu des grains mis en réserve), et qui symbolisait son rôle de garant de la prospérité de la communauté [22]. Selon F. Coarelli, il s'agissait de cultes privés de la maison du roi, ce qui expliquerait pourquoi l'aedes Vestae n'a jamais été un temple inauguré (templum) [23], et que les sanctuaires de Mars et d'Ops Consiva à la Regia étaient définis comme des sacraria, c'est-à-dire des lieux qui n'avaient pas été consacrés à une divinité, mais dans lesquels étaient simplement conservés des objets sacrés (ce qui se rencontre également in aedificio privato) [24]. Avec le départ de Tarquin le Superbe et le renversement de la royauté à Rome, cet ensemble palatial aurait volé en éclats et ses différentes parties auraient été consacrées chacune à un élément particulier du culte publique de la nouvelle Res publica : le culte de Vesta, auparavant honoré par les filles du roi, aurait dorénavant été pratiqué dans l'aedes Vestae par les Vestales, prêtresses publiques hébergées dans ce qui est devenu l'atrium Vestae; le pontifex maximus, devenu le chef de la religion publique de la cité, se serait retrouvé à la place du roi dans la domus publica ; et la partie de l'ancien palais royal consacrée aux cultes de Mars et d'Ops Consiva serait devenue la Regia républicaine où officiait le rex sacrorum, un prêtre placé sous la tutelle du pontifex maximus au sein du collège des pontifes. Mieux encore : à l'instar de F. E. Brown, F. Coarelli voulait voir dans les différentes phases architecturales de la Regia, comme dans celles du Comitium ou du sanctuaire archaïque de l'area sacra di S. Omobono,
[18] Aelius Stilo, dans Grammaticae Romanae Fragmenta, fr. 34 Funaioli (chez Festus, p. 439 L., s.v. Salias virgines) ; Festus, p. 190 L., s.v. October equus ; Paul Diacre, Extraits tirés de Festus, p. 191 L., s.v. Octuber equus ; Macrobe, Saturnales, I, 15, 19 ; I, 16, 30 ; Varron, La langue latine, VI, 12. Voir DUMÉzIL 1974, p. 225-238; ID. 1975, p. $177-219$; COARELLI 1986 , p. 72-74.

[19] BRown 1967.

[20] CoARELLI 1986, p. 56-79.

[21] CoARelLi 1986, p. 62 : « È dunque probabile che la Regia costituisca il nucleo più antico di un'abitazione regale, che si sarà estesa più ampiamente in seguito ».

[22] POUTHIER 1981, en part. p. 59-78 (« Ops Consiva in Regia »).
[23] Cf. Varron (chez Aulu-Gelle, Nuits attiques, XIV, 7, 7) : « Parmi ces indications il (sc. Varron) a laissé aussi écrit que tous les édifices sacrés (aedes sacrae) ne sont pas des temples (templa) et que même l'aedes de Vesta n'est pas un temple (templum) » (trad. R. Marache, Paris, CUF, 2002). Servius, Commentaire sur l'Énéide de Virgile, VII, 153 : «(...) le temple de Vesta n'a pas été consacré au moyen d'un signe augural (augurium) (...) ».

[24] Voir Ulpien, Sur l'Édit du préteur, 68 (dans Digeste, I, 8, 9, 2) : « Il faut noter qu'un lieu sacré (sacer locus) est une chose, un sacrarium en est une autre. Un lieu sacré est un endroit qui a été consacré, alors qu'un sacrarium est un endroit dans lequel des objets sacrés ont été déposés, ce qui peut aussi exister dans un édifice privé ». 
entrecoupées d'incendies et de destructions violentes, l'écho des luttes politiques pour le pouvoir royal et la correspondance chronologique avec les différents règnes qui se seraient succédé entre le dernier quart du $\mathrm{VII}^{\mathrm{e}}$ siècle et la fin $d u \mathrm{VI}^{\mathrm{e}}$ siècle av. J.-C. (la date de 625 à laquelle correspondent les premières phases architecturales de ces différents monuments correspond effectivement, grosso modo, au début du règne de Tarquin I'Ancien d'après la chronologie établie par la tradition littéraire) [25]. F. Coarelli appuyait sa reconstruction en combinant les données archéologiques et le témoignage des sources littéraires sur la topographie religieuse de l'ensemble du secteur, mais aussi en comparant ces données avec celles des complexes palatiaux qui avaient été récemment découverts en Étrurie, à San Giovenale, à Murlo (Poggio Civitate) et à Acquarossa [26].

Toutefois, si I'on s'en tient au témoignage des sources littéraires comme le fait F. Coarelli, celles-ci semblent plutôt infirmer l'idée d'un ensemble palatial unique sur le Forum dans lequel auraient résidé les différents rois : à part le roi Numa qui est censé avoir passé tout son temps dans la Regia (ce qui peut s'expliquer par l'importance des innovations religieuses que la tradition lui attribue), tout en habitant également sur le Quirinal (ce qui était aussi logique pour un Sabin censé venir de Cures) [27], les autres rois auraient occupé divers lieux de résidence, tous en-dehors du Forum [28]. Le témoignage-clé à ce sujet est celui de Solin, qui s'inspire probablement de Varron : selon lui, Titus Tatius aurait habité dans la citadelle du Capitole (arx), à l'emplacement du futur temple de Junon Moneta ; Numa aurait d'abord habité au Quirinal, avant de s'installer à côté de l'aedes Vestae, dans un bâtiment qui fut pour cette raison appelé Regia ; Tullus Hostilius aurait habité sur la Vélia, où sera plus tard construit le temple des Pénates; Ancus Marcius en haut de la via Sacra (in summa sacra via), où se trouvera le temple des Lares; Tarquin
I'Ancien près de la porte Mugonia, « au-dessus de la via Nova » (supra summam novam viam), donc au pied du Palatin ; et Servius Tullius ainsi que Tarquin le Superbe auraient tous deux habité sur I'Esquilin (I'un sur le clivus Urbius, ou Orbius, et I'autre sur le clivus Pullius, près du lac Fagutal) [29]. De plus, le rex sacrorum lui-même semble avoir habité ailleurs que dans la Regia, quelque part sur la via Sacra entre la Regia et le sacellum de Strenia, au lieu-dit les Carinae (situées dans la dépression entre la Vélia et le Fagutal) [30]. Pour être franc, ni la documentation archéologique ni les sources littéraires ne permettront jamais de déterminer où pouvaient bien résider les différents rois de Rome. Par contre, les ruines de la Regia combinées au témoignage des sources littéraires peuvent permettre de mieux comprendre le rôle et les fonctions du rex sacrorum, et derrière ceux-ci, l'évolution institutionnelle qu'a connue la cité aux époques archaïque et alto-républicaine.

Pour en revenir à F. E. Brown, en 1974, celui-ci changea d'opinion par rapport à sa première vision de I'histoire de la Regia : la Regia républicaine serait en fait la dernière version d'une série de constructions similaires commencées dès 625 av. J.-C. [31]. Certes, les diverses phases de construction diffèrent les unes des autres par leur organisation interne, et la cinquième Regia (à partir de 500 av. J.-C. environ) présente un nouveau plan au sol qui restera inchangé jusqu'au Principat, malgré les reconstructions successives. Mais F. E. Brown voyait désormais dans les phases antérieures de construction les précurseurs de la Regia républicaine également pour leurs fonctions, puisqu'on retrouve dans chacune d'elles les mêmes éléments de base constitués par la présence de deux petites chambres associées à une cour portiquée de forme irrégulière. Il en déduisit que la construction devait avoir les mêmes fonctions depuis ses origines, et qu'elle n'a jamais pu être un lieu de résidence à aucun moment de son évolution. Par conséquent,
[25] Brown 1974-1975, p. 35 ; CoARelli 1986, p. 60-70 et p. 137-138; cf. aussi Staccioli 1981.

[26] Cf. Torelli 1981, p. 174-181; ID. 1993 ; Stopponi (éd.) 1985 , p. $21-22$; p. 41-57 ; p. 64-69. Voir surtout la contribution de D. Briquel dans ce dossier.

[27] Ovide, Fastes, VI, 263-264 (infra n. 73) ; Tristes, III, 1, 30 ; Plutarque, Numa, 14, 1-2 (infra n. 73) ; Tacite, Annales, XV, 41 ; Dion Cassius, fr. 6, 2 ; Solin., I, 21 (infra n. 73) ; Servius, Commentaire sur l'Énéide de Virgile, VII, 153 ; VIII, 363.

[28] CORNELL 1995, p. 239-241.
[29] Solin., I, 21-26 ; cf. Varron, La vie du peuple romain, I, fr. 7 Riposati $=289$ Salvadore (chez Nonius, p. 852 , I. $19-21$ L.). Voir CoARelLi 1986, p. 56-58 ; sur le lieu de résidence de Servius Tullius sur I'Esquilin, voir ID. 2001 ; sur celui d'Ancus Marcius, voir Camous 2004, p. 192-195; cf. CARANDINI 1997, p. 511.

[30] Festus, p. 372 L., s.v. Sacram viam (infra n. 91); Servius Daniel, Commentaire sur l'Énéide de Virgile, VIII, 363. Voir CoARELLI 1986, p. 21-26 ; ID. 1999b ; PAPI 1995 , p. 169-170 ; RodRÍGeZ Almeida 1993, p. 239-240 ; cf. PALOMBi 1997, p. 49-51; p. 137-139.

[31] BRown 1974-1975, p. 15-36 ; cf. LOSEHAND 2007. 
la Regia républicaine, comme la Regia royale, n'était pas une résidence, mais un édifice sacré contenant les sacraria de Mars et d'Ops Consiva, qu'il identifiait avec les deux chambres présentes à chacune des phases de sa construction. La chambre la plus grande, équipée d'un foyer, est identifiée avec le sacrarium Martis qui abritait, d'après nos sources, les talismans guerriers les plus précieux de Rome : c'est là que se trouvaient les hastae Martis dont le frémissement annonçait un présage menaçant ; c'est là que se trouvaient également les douze anciles, boucliers sacrés dont I'un aurait été envoyé du ciel par Mars lui-même pour assurer la cité de Romulus de sa protection particulière, et qui étaient placés sous la garde des prêtres saliens ; c'est là enfin que se rendait tout nouveau titulaire de l'imperium militiae avant de rejoindre son armée pour partir en campagne, afin d'aller y remuer les anciles et y toucher la lance de la statue de Mars en disant : Mars vigila ! [32] La chambre la plus petite est par contre identifiée avec le sacrarium d'Ops Consiva : d'après Varron, son sanctuaire était tellement « étroit » (manuscrits : $a<r>c t u m$ ) [ou « auguste » (augustum) ?] que seules les Vestales accompagnées du «prêtre public » (sacerdos publicus) pouvaient y pénétrer [33]. Les exégètes et les traducteurs du texte de Varron interprètent généralement I'expression sacerdos publicus comme devant désigner le pontifex maximus [34], mais rien n'interdit de penser qu'il pouvait d'abord s'agir, au moins à l'origine, du rex sacrorum. En effet, au cours de la période républicaine ou à la fin de la République, le pontifex maximus, qui habitait la domus publica, aurait vu une partie de ses compétences religieuses s'étendre à la Regia, en finissant par éclipser le rôle qu'y avait traditionnellement joué le rex sacrorum (voir infra). F. Coarelli a essayé de préciser ce processus historique en estimant que le pontifex maximus aurait remplacé le rex sacrorum dans ses principales fonctions religieuses au cours du $\mathrm{II}^{\mathrm{e}}$ siècle av. J.-C., en prenant alors également possession de sa maison : la domus publica du grand pontife doit dès lors être identifiée avec la domus regis sacrorum, qui serait en fait son nom officiel, et il s'agissait accessoirement d'une « demeure publique » parce qu'elle était réservée au «prêtre public » (sacerdos publicus) [35].

\section{LE « ROI » DANS LA HIÉRARCHIE SACERDOTALE ARCHAÏQUE}

À la fin de la République ou sous l'Empire, le rex sacrorum n'exerçait plus qu'un rôle relativement secondaire dans la religion publique de l'État romain, au point de se trouver subordonné au pontifex maximus : c'est dans cette situation de subordination par rapport au grand pontife que Tite-Live I'imagine dès sa création en 509 [36]. En fait, le « roi des rites sacrés » semble avoir primitivement exercé des fonctions religieuses de première importance pour la cité et avoir occupé une place toute différente dans la hiérarchie sacerdotale. Le témoignage le plus sûr de la primauté primitive du rex sacrorum dans la religion romaine est fourni par un passage de Festus sur l'ordo sacerdotum :

Ordo sacerdotum aestimatur deorum <ordine, ut deus> [37] maximus quisque. Maximus videtur Rex, dein Dialis, post hunc Martialis, quarto loco
[32] Servius, Commentaire sur l'Énéide de Virgile, VII 603 ; VIII, 3. Voir DumÉZIL 1974, p. 40-43; p. 185 ; Brown 1974-1975, p. 35 ; CoARelli 1986, p. 62.

[33] Varron, La langue latine, VI, 21 : « Le jour des Opiconsivia tire son nom de la déesse Ops Consiva, qui a, dans la Regia, une réserve cultuelle (sacrarium) tellement sainte (augustum) que personne n'y pénètre à l'exception des Vestales et du prêtre public (sacerdos publicus). Quand celui-ci y va, qu'il porte un suffibulum (voile), telle est la prescription » (trad. P. Flobert, Paris, CUF, 1985). Voir DUMÉZIL 1974, p. 168-169 ; p. 185 ; BROWN 19741975, p. 35-36 ; CoARelLi 1986, p. 62.

[34] Cf. Flobert 1985 , p. 93 ( $\S 21$, n. 3) : [« prêtre public » :] « Le Grand Pontife, qui a la haute main sur les six Vestales ».

[35] Coarelli 1986, p. 21-26 ; cf. ScotT 1995 ; sur la domus regis sacrorum devenue la domus publica du grand pontife, voir aussi supra n. 6 .

[36] Tite-Live, II, 2, 1 : « On s'occupa ensuite des affaires religieuses, et comme certains sacrifices publics (publica sacra) étaient habituellement faits par les rois eux-mêmes (per ipsos reges factitata erant), pour éviter que les rois ne fussent regrettés, on créa un "roi des sacrifices" (rex sacrificolus). On soumit ce sacerdoce au pontife (pontifex), afin qu'une fonction éminente (honos) ajoutée à ce titre ne fasse en quoi que ce soit obstacle à la liberté, qui était alors le premier souci ».

[37] F. Van Haeperen (VAN HaEperen 2002, p. 89-92) conteste la restitution du texte de Festus proposée par W. Lindsay (deorum <ordine, ut deus $>$ ), la hiérarchie des prêtres ne pouvant pas être établie d'après celle des dieux, puisque, contrairement aux flamines, les fonctions du rex et du pontifex ne sont pas liées à une divinité particulière : « I'absence de mention des dieux que desserviraient le rex et le pontifex maximus pourrait signifier que la restitution de Lindsay n'est pas acceptable. L'on pourrait suggérer, à titre d'hypothèse, que l'ordo sacerdotum pouvait être estimé, lors des banquets des dieux (deorum <epulis>), selon la place occupée par chacun des prêtres » (p. 92). 
Quirinalis, quinto pontifex maximus. Itaque in <epulis solus> [38] Rex supra omnis accumbat licet ; Dialis supra Martialem, et Quirinalem ; Martialis supra proximum; omnes item supra pontificem. Rex, quia potentissimus ; Dialis, quia universi mundi sacerdos, qui appellatur Dium; Martialis, quod Mars conditoris urbis parens ; Quirinalis, socio imperii Romani Curibus ascito Quirino ; pontifex maximus, quod iudex atque arbiter habetur rerum divinarum humanarumque.

« La hiérarchie des prêtres est estimée < d'après le rang> des dieux, <selon> l'importance de chaque <dieu>. Le rex est considéré comme le plus grand, puis vient le flamine de Jupiter ; après lui, celui de Mars, en quatrième lieu, celui de Quirinus ; au cinquième rang, le grand pontife. C'est pourquoi dans les banquets sacrés (in epulis), le rex se place seul sur le lit au-dessus de tous. De même le flamine de Jupiter prend place au-dessus de celui de Mars et de Quirinus, et celui de Mars au-dessus de ce dernier. De même, tous prennent place au-dessus du pontife. Le rex, parce qu'il est le plus puissant ; le flamen Dialis parce qu'il est le prêtre du monde entier, qui est appelé Dium ; le flamine de Mars, parce que Mars était le père du fondateur de Rome ; le flamine de Quirinus, parce que Quirinus avait été appelé de Cures pour être associé au pouvoir romain (imperium Romanum) ; le grand pontife, parce qu'il est considéré comme le juge et l'arbitre des affaires divines et humaines. »

Festus, p. 198-200 Lindsay.

Dans ce document, le « roi » (rex) est explicitement présenté comme un prêtre (sacerdos) : il ne peut dès lors s'agir que du rex sacrorum. C'est d'ailleurs ce que confirment deux autres témoignages analogues, rapportés par Aulu-Gelle et par Servius, qui semblent se référer au même ordo sacerdotum, c'est-à-dire à celui qui se manifestait par la place occupée par chaque prêtre lors des banquets des dieux (deorum epulis) [39] : il est d'ailleurs possible que les trois auteurs dépendent d'une source commune qui pourrait provenir de la littérature

[38] Les manuscrits indiquent tous : in solus Rex ; W. Lindsay restitue : in soliis Rex; je m'inspire ici de la solution proposée par l'editio princeps (Milan, 1500 : in conviviis solus Rex), mais je préfère in epulis à in conviviis (voir aussi supra n. 37).

[39] Aulu-Gelle, Nuits attiques, X, 15, 21 : «Personne ne se place au-dessus du flamine de Jupiter dans un banquet (in convivio), excepté le roi des sacrifices (rex sacrificulus) ». Servius, Commentaire sur l'Énéide de Virgile, II, 2 : «"Du haut de son lit de table" (TORO AB ALTO) : la place la plus élevée est en effet pontificale ; il n'est en effet pas permis que quelqu'un s'étende sur le lit de table au-dessus du roi des sacrifices (rex sacrificulus) ». Voir auss supra n. 37. juridico-religieuse, comme les Libri iuris pontificis de Fabius Pictor cités comme source par Aulu-Gelle pour sa notice sur le flamen Dialis [40]. Le texte de Festus présente par conséquent la hiérarchie des prêtres (ordo sacerdotum) d'après un document religieux probablement très ancien : le « roi » (« des sacrifices ») est présenté au sommet de la hiérarchie sacerdotale, suivi par les trois flamines majeurs (flamen Dialis, flamen Martialis et flamen Quirinalis), et enfin par le pontife (pontifex). Ce dernier est généralement considéré comme étant le grand pontife, mais la phrase de Festus (omnes item supra pontificem) n'indique pas l'épithète maximus, ce qui signifie que ce prêtre était alors l'unique pontife de la religion romaine [41]. D'ailleurs, lorsque Tite-Live évoque la création du rex sacrificulus en 509, il précise immédiatement que ce sacerdoce aurait alors été soumis au pontife (pontifici), mentionné au singulier et sans épithète (qu'on comprend généralement comme étant le pontifex maximus) [42].

Le groupe de prêtres présenté par l'ordo sacerdotum correspond au plus ancien noyau du futur collège pontifical, le plus important des quatre collèges sacerdotaux d'époque républicaine (pontifes, augures, decemviri [puis quindecemviri] sacris faciundis, triumviri [puis septemviri] epulones) : il est même probable qu'il constituait, avec celui des augures, le plus ancien collège sacerdotal à Rome [43]. Le texte qu'avait déniché Verrius Flaccus présentait le groupe de prêtres suivant une hiérarchie différente de celle de la fin de la République, puisque le rex (sacrorum) est situé au sommet de la hiérarchie sacerdotale, tandis que le pontife, alors encore unique, lui était subordonné et était placé en dernier dans l'ordre protocolaire du collège. La hiérarchie présentée par ce document concerne certes la place occupée par chaque prêtre dans les banquets sacrés (in epulis), mais comme il s'agit de banquets rituels organisés dans le cadre de

[40] Fabius Pictor, Iuris pontificii libri, fr. 2 Peter $=3$ Huschke (chez Aulu-Gelle, Nuits attiques, X, 15, 1) ; voir Beard, North \& Price 1998, p. 197, n. 1 ; Bianchi 2010, p. 110-121 ; sur l'identité de ce (Serv. ou N. ?) Fabius Pictor (probablement un auteur du $\mathrm{II}^{\mathrm{e}}$ siècle av. J.-C.), voir Suerbaum 2014, p. 387-389 et p. 597.

[41] Seguin 1988, p. 409-412.

[42] Tite-Live, II, 2, 1 (voir supra n. 36) ; cf. LoICQ 2004, p. 233 : « en présentant le 'roi des sacrifices' comme étant de propos délibéré subordonné au grand pontife, I'annalistique commet un anachronisme. »

[43] DUMÉZIL 1974, p. 567-579 ; SCHEID 2001, p. 61-62 ; Van Haeperen 2002, p. 80-88; Bianchi 2010, p. 113-121. 
leurs fonctions cultuelles, la hiérarchie sacerdotale a ici une valeur générale, même si elle trouve dans ces banquets sa manifestation concrète [44]. Une telle hiérarchie sacerdotale n'a pas pu se constituer pendant la période républicaine, quand le pontifex maximus était devenu le véritable chef de la religion publique (au point que l'exercice de la fonction deviendra ultérieurement un élément fondamental dans les pouvoirs attribués au Prince) : elle ne peut donc correspondre qu'à un ordre archaïque, bien plus ancien [45].

Le titre sacerdotal rex (tout court), attesté également par Varron [46], indique que le complément du nom sacrorum ou l'adjectif épithète sacrificulus n'ont été ajoutés que plus tard, probablement lorsque l'odium regni qui animait l'idéologie de I'aristocratie romaine républicaine et ses principes de libertas a imposé la nécessité de distinguer cette fonction purement sacerdotale de la fonction politique du roi (optimo iure) [47]; cette distinction sémantique et idéologique a pu s'accompagner d'une assimilation délibérée du rex (sacrorum) romain au

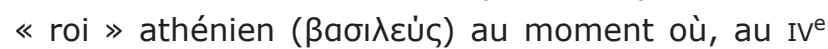
siècle, Rome cherchait à se présenter sur la scène
« internationale » comme une mó $\lambda$ is $\dot{\lambda} \lambda \lambda \eta$ vís [48]; en tout cas, le simple mot rex pour désigner le « roi des rites sacrés » ne peut renvoyer qu'à une époque très ancienne de la République, voire antérieure à elle [49]. L'antiquité de ce sacerdoce est d'ailleurs indiquée par la prescription obligeant ce prêtre à appartenir à une famille patricienne et à être né de parents mariés selon le rituel patricien de la confarreatio [50]. Or le mot rex (tout court) pour désigner la fonction sacerdotale exercée à l'époque républicaine par le rex sacrorum fait immédiatement penser à l'inscription archaïque qui figure sur le fond de la grande coupe en bucchero retrouvée sous le niveau républicain de la Regia (fig. 2) et qui est datée de la seconde moitié du vi ${ }^{\mathrm{e}}$ siècle (530-510 environ). La coupe devait servir aux libations qui se déroulaient à l'intérieur de la Regia archaïque, lors des banquets sacrés (epula) évoqués par le texte de Festus, et le graffito indique simplement qui devait ou pouvait se servir de la coupe [51]. L'ordo sacerdotum rapporté par Festus/Verrius Flaccus constitue par conséquent un «fossile » d'une époque antérieure à la prédominance du pontifex maximus dans la religion romaine, et pourrait même renvoyer à
[44] Van Haeperen 2002, p. 89-92; Bianchi 2010 , p. 111 . Voir supra n. 37.

[45] DuMÉZIL 1942, p. 73 ; ID. 1958, p. 48-49; ID. 1974 , p. 122 ; LOICQ 2004 , p. $233-234$; BIANCHI 2010 p. $11-12$; selon VAN HAEPEREN 2002, p. 92 : « Il est vraisemblable que cette hiérarchie, subsistant en certaines occasions, soit un témoin résiduel de relations beaucoup plus anciennes entre rex, flamines et pontifex ; cet ordre serait ainsi le reflet d'une époque lointaine où le rex était encore, effectivement, potentissimus et résumait, en sa personne, les trois fonctions que représentait, séparément, chaque flamine, tandis qu'il était secondé, pour le traitement des affaires religieuses, par le pontifex, actif et engagé dans le temps. »

[46] Varron, La langue latine, VI, 12 : « Les jours Agonales, au cours desquels le roi (rex) immole un bélier dans la Regia, ont reçu leur appellation d'agone ("y vais-je ?"), parce que la question est posée par le premier personnage de la cité (a principe civitatis) et que le premier (princeps) du troupeau est immolé » (trad. d'après P. Flobert, Paris, CUF, 1985).

[47] Le problème sémantique posé par le titre sacerdotal rex dans le contexte politique et idéologique du Ive siècle est d'ailleurs clairement exprimé par Tite-Live, dans la diatribe qu'il attribue au tribun de la plèbe $P$. Sempronius contre le censeur Appius Claudius en 310 (IX, 34, 12) : «Qui créeras-tu roi des sacrifices (rex sacrificiorum) ? Une fois qu'il se sera empressé d'accepter le titre de la royauté (regni nomen), il se dira nommé (creatus) comme celui qui a été nommé roi de Rome de plein droit (optimo iure) 》.

[48] Cf. Tite-Live, II, 2, 1 (voir supra n. 36) ; Denys d'Halicarnasse, Antiquités Romaines, IV, 74, 4 (voir supra n. 9) ; voir SMITH 2011, p. 40. Sur l'odium regni dans I'idéologie politique de la République romaine, voir notamment : MARTIN 1994, passim, en part. p. 3-30 Russo 2015 ; sur Rome módis $\dot{\varepsilon} \lambda \lambda$ пvís au Ive siècle av. J.-C. (cf. Héraclide du Pont, fr. 102 Wehrli, chez Plutarque, Camille, 22, 3), voir notamment : VANOTTI 1999 ; STOUDER 2011.

[49] LoIcQ 2004, p. 233-234, a montré que la forme sacrorum ne peut pas remonter au début de la République (« on attendrait *sacrom, les désinences arum, -orum étant secondaires »), et que la forme initiale a plutôt été rex sacrificulus (attestée par les inscriptions et par plusieurs occurrences chez Tite-Live et Festus), ce qui n'implique toutefois pas l'antiquité de l'expression, car « cette spécification n'était (...) plus nécessaire dès l'instant où le pouvoir était détenu par un magister » (voir infra) ; voir aussi OAKLEY 2005, p. 438-439; BIANCHI 2010, p. 25, n. 66.

[50] Cicéron, Sur sa maison, 38 ; Tite-Live, VI, 41, 9 ; Gaius, Institutes, I, 112. BendLIn 2001, col. 937.

[51] CIL I ${ }^{2}$ 2830. Selon GuarducCI 1972, I'incision du seul nom de la fonction au nominatif, sans autre précision (mais sous-entendu habet ou possidet ou utitur) fait penser que la coupe devait servir au « roi-prêtre » dans un contexte officiel ; I'auteur remarque que I'on attendrait certes plutôt un génitif, mais qu'il ne manque pas d'exemples, pour l'époque archaïque ou alto-républicaine, d'objets « parlants », notamment des vases, portant un nom au nominatif, parfois précédé par le mot ego (CIL I 474 : $E<Q=g>0$ K(aeso) An(n)aios ; CIL I ${ }^{2}$ $479: E<Q=g>0$ Fulfios ; $C I L \mathrm{I}^{2} 480: L$ (ucius) Suro(nius) Ligus) ; I'utilisation du nominatif rex peut donc aussi s'expliquer sans verbe sous-entendu : le graffito indiquerait tout simplement la personne qui est censée utiliser I'objet, vraisemblablement au cours des banquets sacrés (epula) organisés dans la Regia ; voir en dernier lieu sur ce point : LoICQ 2004, p. 236-238. 
une réalité religieuse antérieure à l'instauration de la République [52].

Alors que les flamines étaient des « prêtres-statues » (J. Scheid) qui incarnaient chacun l'un des trois dieux de la vieille triade romaine pré-capitoline (Jupiter, Mars, Quirinus), en ayant le rôle passif de prêtres « possédés » par leur dieu (sans avoir «le pouvoir d'actualiser, d'interpréter, ni de répondre à une nécessité nouvelle ») [53], le pontife avait un rôle actif en charge de l'administration des cultes, afin de veiller à la continuité des rites sacrés et à leur régulière actualisation [54] : il était donc un expert dans la science du sacré [55] et s'occupait à ce titre des relations entre la communauté et ses dieux, d'où il tirait son expertise juridique et ses fonctions de consultant et d'interprète du sacré [56]. Il est difficile de connaître I'origine du pontificat, mais il semblerait que le pontifex ait toujours disposé d'une liberté d'initiative au sein du collège sacerdotal, surtout par rapport aux flamines, et notamment par rapport au flamen Dialis. En fait, les deux types de sacerdoces (le flaminat et le pontificat) se complétaient dans le domaine du sacré au centre duquel se trouvait le rex : celui-ci était également un prêtre actif, à l'origine assisté du pontife, tout en faisant la synthèse des trois fonctions incarnées par chacun des trois flamines majeurs [57]. Pour G. Dumézil, le rex était ainsi à la fois «souverain, diseur de droit et adorateur des dieux, mais aussi guerrier, nourricier et protecteur de la masse populaire », et la disposition matérielle de la Regia reproduisait fidèlement la plus ancienne idéologie de son sacerdoce, puisque s'y juxtaposaient : les sacrifices offerts dans la cour par le rex, la regina et la flaminica Dialis, et destinés soit à Jupiter, soit à Junon et à Janus en tant que régulateurs du temps (aux calendes, aux nondines et en janvier) ; des rituels militaires de Mars effectués dans un sacrarium spécial ; et enfin des rituels d'Ops Consiva, déesse de l'abondance agricole, effectués dans un autre sacrarium [58].

Mais I'ordre hiérarchique des sacerdoces présenté par le texte de Festus correspond probablement aussi à l'ordre chronologique de leur création respective : le rex, dans la théorie dumézilienne, serait I'héritier du *reg-indo-européen, assimilable au raj(an) védique ou au rí irlandais, et constituerait le prolongement d'une tradition indo-européenne de sortes de « roisprêtres » [59] ; quant aux flamines majeurs, attachés au culte de Jupiter, Mars et Quirinus, et étroitement associés au rex (particulièrement le flamen Dialis) [60], leur origine doit remonter à une époque où cette triade n'avait pas encore été remplacée par la triade capitoline d'origine étrusque, au $\mathrm{vI}^{\mathrm{e}}$ siècle (I'archaïsme de ce sacerdoce est également suggéré par son nom, que G. Dumézil rapprochait de celui des brahmanes védiques [61], ainsi que par les prescriptions particulièrement archaïques attachées au flamen Dialis) ; la création du pontificat semble par contre relativement plus récente, ce qui peut expliquer sa place dans l'ordo sacerdotum [62]. D'ailleurs, parmi les flamines, ceux de Jupiter, Mars et Quirinus ont été appelés majeurs par rapport aux autres, appelés mineurs (minores), parce qu'ils étaient les plus anciens (maiores), comme le pontifex, à
[52] Van Haeperen 2002, p. 88-96; Bianchi 2010, p. 126-128; comme le souligne E. Bianchi, I'hypothèse avancée par K. Latte selon laquelle I'ordo sacerdotum, tel que rapporté par le texte de Festus, ne se serait fixé que vers 350 av. J.-C., lorsque se serait affirmée l'autorité pontificale, est évidemment absurde : cf. LATTE 1960, p. 37 et p. 96 .

[53] DuMÉZIL 1974, p. 572-573 ; SCHEID 2001, p. 55-61 (cf. Plutarque, Questions Romaines, 111 [Mor., 290 C] : « le prêtre de Jupiter, à l'instar d'une statue vivante

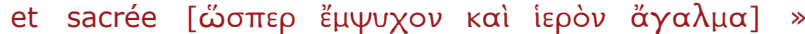
[trad. J. Boulogne, Paris, CUF, 2002]) ; RüPKE 2005, p. $1415-1416$.

[54] Pour DumÉzIL 1974, p. 574, « son titre [pontifex : « celui qui fait le, un pont » ou « un chemin »] met en évidence son devoir, son privilège d'activité »; VAN HAEPEREN 2002 , p. 94, souligne que « le nom même de pontifex est mis en rapport avec une action (-fex) tant par les anciens que par les modernes. Peu importent les diverses étymologies proposées, toutes présentent ce trait commun : le pontife est une personne caractérisée par un agir. »

[55] Cicéron, Des lois, II, 47 : « En quoi le droit des murs (de iure parietum), celui des eaux (aut aquarum) ou de n'importe quelle autre chose (aut ullo omnino) concerne-t-il le pontife, si ce n'est lorsqu'il se rattache de quelque manière à la religion ? (...) Je crois qu'il se limite au droit relatif aux obligations sacrées (de sacris), aux vœux (de votis), aux jours de fête (de feriis) et aux tombeaux (de sepulcris), et si cela concerne quelque chose de ce genre ».

[56] Voir notamment : DumÉZIL 1974, p. 573-574 ; BRETONe 1997, p. 107-112; SCHEID 2001, p. 61-63; ID. 1992, p. 97-104 ; VAN HAEPEREN 2002, p. 67-77; p. 215-341.

[57] Dumézil 1974, p. 574-576; Van Haeperen 2002, p. 92 ; BIANCHI 2010, p. 11.

[58] DuMÉZIL 1954 ; ID. 1961 ; ID. 1974, p. 184-186 et p. 575-576.

[59] DumÉZIL 1974, p. 34-35 ; p. 568-569.

[60] Le flamen Dialis partageait avec le rex un culte commun au plus vieux Jupiter, qui portait le titre de Rex (cf. Cicéron, La République, I, 50 ; Tite-Live, III, 39, 4) : DumÉZIL 1974, p. 164 ; p. 339 ; MARCO Simón 1996.

[61] DuMÉZIL 1974, p. 95-96 ; p. 221 ; p. 570-572 ; cf. aussi SCHEID 2001, p. 55.

[62] Voir la synthèse à ce sujet par SzemLer 1978, col. 342-346. 
I'origine unique, a fini par être appelé maximus parce qu'il était plus ancien au sein du collège (et donc aussi plus important) que les autres pontifes créés ultérieurement [63]. On a donc l'impression que le collège sacerdotal évoqué par l'ordo sacerdotum a été créé progressivement par adjonction successive des flamines puis du pontife, afin d'aider le prêtre « roi » dans ses fonctions religieuses. Le rex était par conséquent le prêtre le plus important aussi parce qu'il était le plus ancien.

Par contre, la primauté du pontifex maximus est clairement attestée à l'époque médio-républicaine. Ainsi, d'après Tite-Live, lorsqu'il fallut remplacer les pertes dues à une épidémie de peste en 180 av. J.-C., c'était au pontifex maximus de désigner le rex sacrorum, au besoin en recourant à des moyens coercitifs si la personne désignée tentait de se dérober [64]. De la même manière, c'était au pontifex maximus que revenait de « prendre » (capere), c'est-àdire de choisir, les prêtresses vestales qui étaient placées sous son autorité [65]. La perte de la deuxième décade de Tite-Live nous empêche d'avoir une vision précise de la situation au $\mathrm{III}^{\mathrm{e}}$ siècle, mais nous savons que pendant la première guerre punique, en
242, le consul A. Postumius Albinus fut empêché par le grand pontife Caecilius Metellus de quitter Rome parce qu'il était flamen Martialis et qu'il ne lui permit pas d'abandonner ses fonctions sacrées [66]. Pour le IV ${ }^{\mathrm{e}}$ siècle, un sarcophage retrouvé dans la tombe des Cornelii sur la via Ardeatina atteste, par son épitaphe, de l'existence d'un pontifex maximus dénommé P. Cornelius Scapula : la mention de cette unique fonction, à côté du nom, suggère qu'on devait la considérer comme la charge la plus importante [67]. Ce Cornelius Scapula correspond peut-être, si I'on suit une hypothèse de F. Coarelli et $\mathrm{d}^{\prime} \mathrm{H}$. Etcheto, au grand pontife P. Cornelius Barbatus évoqué par Tite-Live à propos du conflit ouvert avec l'édile curule Cn. Flavius, au moment de la dédicace de l'aedicula Concordiae sur le Comitium en 304 [68] (c'est d'ailleurs le même $\mathrm{Cn}$. Flavius qui aurait dérobé aux pontifes les formules de procès, ou legis actiones, pour les rendre publiques et créer le ius Flavianum [69]). En tout cas, d'après Tite-Live, c'est seulement à l'extrême fin du IV ${ }^{\mathrm{e}}$ siècle que le nombre de pontifes augmenta (au moment du vote du plébiscite ogulnien, en 300, on aurait porté leur nombre à neuf : rex, flamines majeurs et grand pontife compris [70]).
[63] Cf. Festus, p. 152 L., s.v. Minorum pontificum maximus : «On appelle "le plus grand" (maximus) des pontifes mineurs celui qui est arrivé en premier dans ce collège : de même, on appelle "le plus petit" (minimus) celui qui est le plus récent (novissimus) ». La place de ces prêtres dans la hiérarchie sacerdotale dépend par conséquent de leur ancienneté dans le collège : VAN HAEPEREN 2002, p. 93 ; BIANCHI 2010, p. 123-127.

[64] Tite-Live, $X L, 42,8-10$.

[65] Aulu-Gelle, Nuits attiques, I, 12, 13-14. Voir MeKaCher \& VAN HAEPEREN 2003.

[66] Tite-Live, Abrégés, 19, 11 ; Tite-Live, XXXVII, 51 1-2 ; Valère Maxime, I, 1, 2 ; Tacite, Annales, III, 71, 3.

[67] CIL VI $40893=$ CIL I $2835=A E 1967,19 \mathrm{~b}=A E$ $1971,19=A E$ 1989, $61=A E 2003,87=A E 2009,182$ : $P$ (ublius) Cornelio(s) P(ubli) f(ilius) Scapola / pont(i)fex max(imus).

[68] Tite-Live, IX, 46, 6-7 ; cf. Pline I'Ancien, Histoire naturelle, XXXIII, 19-20. Voir COARELLI 1984, p. 65-69; ETCHETO 2003 ; ID. 2012, p. 158-159 : cet auteur a proposé de reconnaître un seul et même personnage dans les mentions dispersées qui évoquent tour à tour le consul patricien de $328\left(R E, n^{\circ} 316\right)$, le dictateur de $306\left(R E, n^{\circ} 344\right)$, le pontifex maximus de 304 ( $R E$ $n^{\circ} 71$ ) et le P. Cornelius Scapula pontifex maximus connu par l'inscription sur le sarcophage retrouvé sur la via Ardeatina, ce P. Cornelius paraissant avoir été désigné de façon indistincte (ou successive) comme un Scipio, un Barbatus, un Scapula, ou encore un Scipio Barbatus : dans ce cas, la seule mention de son grand pontificat dans son épitaphe traduirait clairement l'importance prise par cette fonction religieuse dans l'aristocratie romaine de la fin du Ive siècle.

[69] Cicéron, Pour Murena, 25 ; Lettres à Atticus, VI, 1 8 ; De l'Orateur, I, 186 ; Tite-Live, IX, 46, 4-5 ; Valère
Maxime, II , 5, 2 ; Pomponius, Enchiridion dans Digeste de Justinien, I, 2, 2, 6-7. Voir Wolf 1980 ; BAUMAN 1983, p. $24-43$; D'IPPOLITo 1985 ; ID. 1986, p. 39-61 ; HumM 2005, p. 444-449 ; LANFRANCHI 2013.

[70] La question de I'évolution du nombre des pontifes est complexe à cause des informations contradictoires livrées par la tradition littéraire : pour Cicéron, Numa aurait créé cinq pontifes (La République, II, 26), mais ce nombre semble inclure l'ensemble des membres du collège pontifical, y compris le rex et les flamines majeurs (donc les cinq membres de l'ordo sacerdotum mentionné par Festus) ; d'ailleurs, pour Servius, le rex était effectivement comptabilisé au nombre des pontifes : Commentaire sur l'Énéide de Virgile, III, 80 : «"Roi et prêtre" (REX ET SACERDOS) : c'était en effet une coutume des anciens que le roi (rex) fût aussi un prêtre ou un pontife (sacerdos, vel pontifex) »; Tite-Live ne parle que d'un seul pontife créé par Numa $(\mathrm{I}, 20,5)$, le pontifex maximus Numa Marcius, mais indique qu'il y en avait quatre en $302(X, 6,6)$, tous encore patriciens à cette date, puis que leur nombre fut doublé en 300, par l'ajout de quatre pontifes plébéiens $(X, 9,2)$; comme, par la suite, le nombre habituel de pontifes et d'augures sera toujours fixé à neuf, on suppose généralement que ce nombre fut atteint par chacun des deux collèges sacerdotaux dès le plébiscite ogulnien de 300 , mais que Tite-Live ne devait pas comptabiliser le pontifex maximus parmi les effectifs qu'il fournit pour les pontifices (en 302 puis en 300), peut-être parce que ce dernier sera élu par les comices tributes à la suite d'une loi comitiale votée entre 292 et 218 , et non coopté comme les autres pontifes ; sur cette question, voir notamment: DE SANCTIS 1907, p. 223-224 et n. 101 ; SzemLer 1978, col. 341-342 ; D'IPPOLITO 1986, p. 95-97 ; SCHEID 1998, p. 112-113; Van Haeperen 2002, p. $108-110$ et p. $120-121$; RüPKE 2005, p. 1621-1622 ; BAUDRY 2008, p. 62-66. 
C'est donc aussi à cette époque que le pontifex maximus a dû prendre l'ascendant au sein du collège pontifical, y compris sur le rex sacrorum : $\mathrm{K}$. Latte a même parlé à ce propos de « révolution pontificale »[71].

\section{LES FONCTIONS DU « ROI » À LA REGIA}

Le pontifex maximus semble en fait avoir accaparé une partie des fonctions auparavant dévolues au rex sacrorum, comme la nomination (captio) des Vestales, qui paraissent avoir été primitivement placées sous l'autorité de ce dernier [72]. Les sources littéraires et archéologiques témoignent de cette ancienne proximité entre le rex et les vestales, à commencer par la proximité topographique entre la Regia et I'atrium Vestae [73]. Ainsi, certains jours dans l'année, les vestales se rendaient chez le rex sacrorum et lui demandaient, selon des paroles rituelles et consacrées : «Vigilasne rex ? Vigila ! »[74]. Il est très probable que ce rituel devait concerner la sécurité de la communauté et qu'il se déroulait dans la Regia, puisque c'est également dans la Regia, au sacrarium de Mars, que les généraux en partance pour la guerre allaient secouer les anciles et la lance de Mars en s'exclamant pareillement : «Mars vigila ! » [75]. Le jour des Opiconsivia, les vestales accompagnaient le « prêtre public » (à l'origine, probablement le rex) dans le sacrarium d'Ops Consiva, la pièce la plus petite et la plus retirée de la Regia, pour y accomplir le sacrifice à la déesse [76]. La Table d'Héraclée indique également la proximité des vestales et du rex sacrorum, et suggère même une sorte de préséance des vestales sur le rex pour le transport en charriots, à I'occasion des cérémonies publiques [77]. De même, l'affichage annuel par le pontifex maximus d'une tabula dealbata sur les murs de la Regia, où le chef de la religion publique consignait brièvement les événements marquants de l'année [78], mais surtout le rôle qu'il jouait dans l'établissement du calendrier annuel, rappellent le rôle exercé précédemment par le rex sacrorum dans I'accomplissement des rites cultuels et des cérémonies religieuses qui rythmaient I'année. Enfin, au moins jusqu'à l'époque de la guerre de Pyrrhus, il existait peut-être une liste permettant de dater un événement d'après le nom du rex sacrorum en fonction et le nombre de ses années de règne [79].
[71] LATTE 1960, p. 195. Dans ce contexte, on peut se demander si P. Cornelius Scapula (supra n. 67 et 68) n'a pas été le premier véritable pontifex « maximus » : cf. RüPKE 2005, p. 921-923 (n॰ 1369 et 1376).

[72] Denys d'Halicarnasse, Antiquités Romaines, III, 67, 2 ; Plutarque, Numa, 10, 1 ; Aulu-Gelle, Nuits attiques, I, 12, 10. Sur la nomination des vestales primitivement par le roi, voir : LATTE 1960, p. 110 ; BIANCHI 2010, p. $134-135$; Mekacher \& Van Haeperen 2003, p. 68-69.

[73] Ovide, Fastes, VI, 263-264 : « Cet espace étroit, qui porte aujourd'hui l'Atrium de Vesta, était alors le grand palais (Regia magna) de Numa, le roi chevelu » (trad. H. Le Bonniec, Paris, Les Belles Lettres, 1990). Plutarque, Numa, 14, 1: «Quand il eut réglé ce qui regardait les sacerdoces, Numa se fit bâtir près du sanctuaire de Vesta

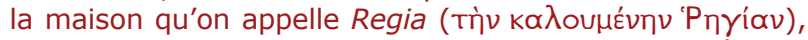
c'est-à-dire, en quelque sorte, le palais royal (oíóv $T$

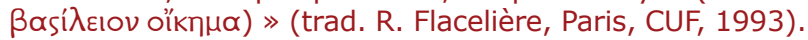
Dion Cassius, I, fr. 6, 2 : « Numa habitait sur la colline appelée Quirinal, parce qu'il était un Sabin, mais il avait sa résidence officielle sur la Voie sacrée, et d'habitude il passait son temps près du temple de Vesta, lorsqu'il restait à son poste ». Dion Cassius, LIV, 27, 3 (supra n. 6). Solin, I, 21 : « Numa habita d'abord sur la colline du Quirinal, puis, près du temple de Vesta (aedes Vestae), à la Regia, lieu qui s'appelle encore ainsi aujourd'hui ». Sur la proximité topographique et fonctionnelle entre la Regia et I'aedes Vestae, voir notamment Ampolo 1971, p. 449-451. [74] Servius, Commentaire sur I'Énéide de Virgile, $\mathrm{X}$, 228: « "Veilles-tu, Énée, descendant des dieux ? Veille !" (VIGILASNE, DEUM GENS, AENEA? VIGILA) : ce sont des paroles de rites sacrés ; car les vierges de Vesta allaient, un certain jour <de l'année> (certa die), auprès du roi des sacrifices (rex sacrorum) et disaient : "Veilles-tu, roi ? Veille!" ».
[75] Servius, Commentaire sur l'Énéide de Virgile, VIII, 3 ; cf. VII, 603. Voir Bianchi 2010, p. 194.

[76] Varron, La langue latine, VI, 21 : voir supra n. 33.

[77] Table d'Héraclée : CIL I² 593, I. 62-63 = FIRA 18 (p. 105) = CRAWFORD 1996, n० 24 (p. 365) : « Les charriots dans lesquels les vestales, le roi des sacrifices, les flamines seront obligés à certains jours de se faire transporter en ville pour accomplir les cérémonies du culte public du peuple romain (...), pourront être pour ces motifs et à ces jours conduits pendant le jour dans la ville $\gg$ (trad. H. Legras, Paris, 1907).

[78] Caton, Origines, fr. 77 Peter $=$ IV, 1 Chassignet (chez Aulu-Gelle, Nuits attiques, II, 28, 4) : «Il ne me plaît pas de rapporter ce qui figure sur la tablette (tabula) du Grand Pontife, combien de fois le cours des denrées a monté, combien de fois un nuage ou quelque autre phénomène a fait écran à la lumière de la lune ou du soleil » (trad. d'après M. Chassignet, Paris, CUF, 1986). Servius, Commentaire sur l'Énéide de Virgile, I, 373 : « Le grand pontife possédait une tablette blanchie (tabula dealbata) annuelle sur laquelle il avait I'habitude de noter les événements dignes de mémoire, en inscrivant en tête les noms des consuls et des autres magistrats, puis les actions menées à l'intérieur et à la guerre (domi militiaeque), sur terre et sur mer (terra marique), jour après jour. On en reporta avec exactitude les commentaires annuels dans quatre-vingts livres anciens, et on les appela les grandes annales (annales maximi) à partir du nom des grands pontifes (pontifices maximi) par lesquels ils furent réalisés ».

[79] Pline I'Ancien, Histoire naturelle, XI, 186. BIANCHI 2010, p. 130-131 ; selon Momigliano 1969, p. 363-364, la notice de Pline pourrait provenir de Timée. 
Une partie de ces activités liturgiques se déroulait dans la Regia et constituait le cœur des fonctions du prêtre « roi ». Quatre fois par an, lors des dies Agonales (le 17 mars, le 21 mai, le 11 décembre et le 9 janvier), le « roi » (《 des rites sacrés »), en tant que princeps civitatis, sacrifiait sur l'autel de la Regia un bélier (princeps gregis) [80]. D'après A. Magdelain, il s'agirait du premier et du plus ancien des rituels accomplis par le « roi »; chaque Agonium aurait été adressé originellement au dieu éponyme du mois (à Mars en mars, à Védiovis en mai, à Indiges en décembre et à Janus en janvier), et les Agonia proviendraient des rituels ayant appartenu à la communauté primitive du Capitole et du Quirinal [81]. Pour B. Liou-Gille, les Agonia constituaient le sacrifice royal par excellence : à l'époque républicaine, ils étaient accomplis par le rex sacrorum, mais ils remontent très probablement à la période royale où ils devaient être accomplis par le roi au plein sens du terme (rex optimo iure), puisque celui-ci était le seul à pouvoir être considéré comme le princeps civitatis [82]. Aux Terminalia (23 février), avant que l'année liturgique archaïque ne se termine, les pontifes demandaient des laines (primitivement appelées februa) au rex sacrorum et aux flamines, dans le cadre de rites expiatoires et de purification [83]. On voit ainsi que les activités rituelles du rex (sacrorum) à la Regia rythmaient l'ensemble de l'année liturgique et faisaient de lui, pour reprendre une image de J. Heurgon, un véritable calendrier vivant [84]. Or le roi « vivait » le calendrier non seulement à la Regia, mais aussi au Comitium.

[80] Varron, La langue latine, VI, 12 (supra n. 46); InscrIt XIII, 2, p. 425-426 (17 Mars) ; p. 460 (21 mai) ; p. 535-536 (11 décembre) ; p. 393-394 (9 janvier).

[81] Varron, La langue latine, VI, 12 ; VI, 14 ; Ovide, Fastes, I, 318-334 ; V, 721-722 ; Paul Diacre, Extraits tirés de Festus, p. 9 L., S.v. Agonium ; Macrobe, Saturnales, I, 4 7-15. Magdelain 1995, p. 18-36 ; BiANCHI 2010, p. 185-188. [82] Liou-Gille 2000 ; BiAnCHI 2010, p. 186-187. Sur l'expression livienne rex optimo iure (opposée à rex sacrificiorum), voir supra n. 47.

[83] Ovide, Fastes, II, 21-22 ; cf. Fasti Antiates Maiores, InscrIt XIII, 2, 1, p. 5 ; p. 414-415.

[84] HeURGon 1969, p. 204-205 : « le roi n'annonçait pas seulement le calendrier, "il le vivait" ».

[85] Cicéron, Pour Murena, 25 ; Lettres à Atticus, VI, 1,8 ; Tite-Live, IX, 46, 4-5 ; Valère Maxime, II, 5, 2 ; Pline I'Ancien, Histoire naturelle, XXXIII, 17 ; Macrobe, Saturnales, I, 15, 9. Voir HUMm 2005, p. 449-480 ; RüPKE 2011, p. 44-50;ID. 2012.

[86] Cicéron, Sur la réponse des haruspices, 12 ; TiteLive, XXII, 57, 3 ; Macrobe, Saturnales, I, 15, 9.

[87] Macrobe, Saturnales, I, 15, 9-10; 15, 19. Voir MiCHeLS 1967, p. 19-21 ; RÜPKE 1995, p. 209-230; ID. 2011, p. 23-37；ID. 2012, p. 85-88.

\section{LE « ROI »AU COMITIUM}

Une partie importante de ses activités rituelles, destinées à marquer les principales étapes du mois et de l'année, se déroulaient en effet en dehors de la Regia, et notamment au Comitium : elles sont néanmoins importantes pour comprendre la véritable nature du « roi » à l'époque archaïque, et donc aussi la fonction de la Regia. Avant la publication des Fastes par l'édile curule Cn. Flavius en 304 et l'établissement du calendrier républicain pré-julien [85], le calendrier romain archaïque était un calendrier de douze mois lunaires qui reposait sur l'observation des phases de la lune (nouvelle lune, pleine lune) : chaque mois, un secrétaire des pontifes (pontifex minor ou scriba pontificius [86]) montait au Capitole pour observer et constater l'apparition de la nouvelle lune ; une fois qu'il avait signalé sa présence visible au rex (sacrorum), celui-ci offrait, avec lui, un sacrifice à Junon Covella près de la curia Calabra, pendant que la « reine des rites sacrés » (regina sacrorum), c'est-à-dire l'épouse du « roi », sacrifiait une truie ou une brebis à Junon dans la Regia [87]. D'après Macrobe, «le même pontife, ayant appelé, c'est-à-dire convoqué, la plèbe au Capitole (in Capitolium), près de la curia Calabra, (...) proclamait le nombre de jours qui devaient s'écouler des calendes jusqu'aux nones » (neuvième jour avant les ides, jour de la pleine lune) [88] ; selon Varron, les calendes auraient été nommées ainsi à partir du verbe calare (« appeler »), parce que ce jour-là
[88] Macrobe, Saturnales, I, 15, 9-10 : « Donc, à l'époque primitive, avant que les fastes eussent été portés à la connaissance publique, contre le gré du Sénat, par le scribe $\mathrm{Cn}$. Flavius, c'est à un pontife mineur qu'était confiée la charge d'observer l'apparition de la nouvelle lune et de signaler sa présence visible au roi des sacrifices (rex sacrificulus). Dans ces conditions, après un sacrifice offert par le roi et le pontife mineur, le même pontife (idem pontifex) ayant appelé, c'est-à-dire convoqué, la plèbe au Capitole, près de la curie Calabre, toute proche de la cabane de Romulus, proclamait le nombre de jours qui devaient s'écouler des calendes jusqu'aux nones, qu'il annonçait pour le cinquième jour en criant cinq fois le mot calo, et pour le septième en le répétant sept fois » (trad. Ch. Guittard, Paris, Les Belles Lettres, 1997) ; cf. Varron, La langue latine, VI, 27-28 (infra n. 89-90). Voir aussi les Fastes Prénestins (InscrIt XIII, 2, 17, p. 111): [A K(alendae) Ian(uariae), f(astus).] (...). Hae et / [ceter]ae calendae appellantur, quia / [pri]mus is dies est quos pont[i]fex minor quo/[libet] mense ad nonas sin[gulas calat] / [in Capi]tolio in curia Cala[bra ( « Jour A = calendes de janvier, jour faste. (...) Ce jour-là ainsi que les autres calendes sont ainsi appelés parce que c'est le premier jour dans n'importe quel mois où le pontife mineur appelle un à un les jours jusqu'aux nones, en étant au Capitole dans la curie Calabra »). 


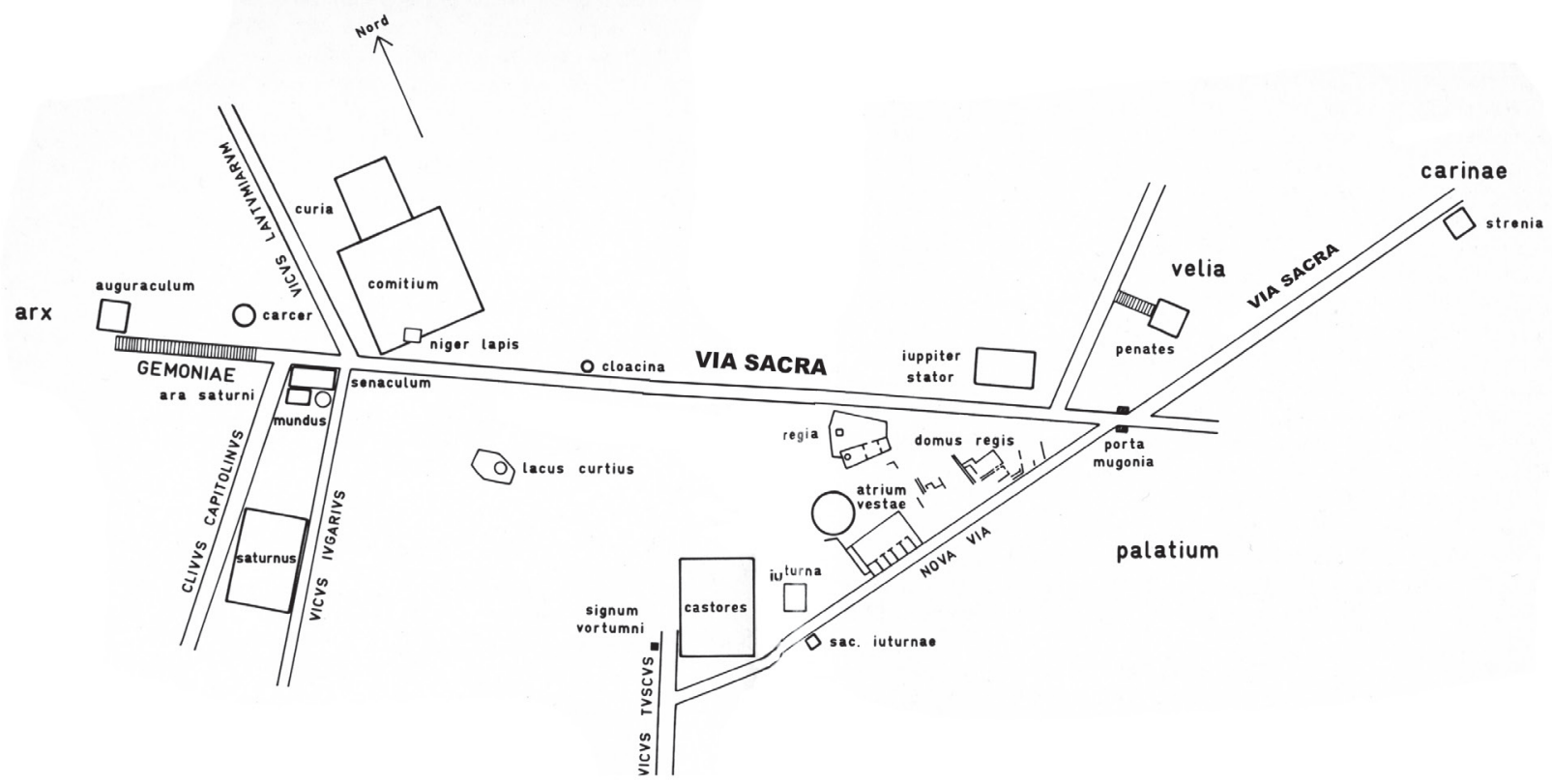

Figure 6

L'« axe » de la via Sacra : Regia - Comitium - Arx (d'après CoARELLI 1986, p. 50-51, @ éditions Quasar, Rome).

Junon Covella était invoquée (calata) cinq ou sept fois, selon le nombre de jours qui séparaient les calendes des nones [89]. Le jour des nones, le rex sacrorum annonçait à la population, convoquée sur I'Arx, les jours fastes et les obligations rituelles du mois (sacra Nonalia) ; le délai écoulé depuis les calendes permettait aux paysans de la campagne d'avoir le temps de se rendre en ville pour entendre I'annonce qui serait faite [90]. Il est remarquable que les trois lieux majeurs où intervenait le rex sacrorum en fonction du calendrier religieux archaïque, la Regia, le Comitium et l'Arx capitoline (curia Calabra), se trouvaient précisément sur l'axe de la via Sacra, qui devait en assurer I'unité fonctionnelle et topographique selon une cohérence qui était encore perçue par les antiquaires de la fin de la République ou du début du Principat, et qui a été soulignée par F. Coarelli [91] (fig. 6). Il s'ensuit que la curia Calabra, où le rex sacrorum se rendait chaque mois, ne devait probablement pas se situer
[89] Varron, La langue latine, VI, 27 : « Le premier jour des mois a été nommé Calendes, parce que c'est le jour où les Nones de ce mois, selon qu'elles doivent être le cinq ou le sept, sont proclamées (calantur) par les pontifes, sur le Capitole dans la curia Calabra ; ainsi il est dit cinq fois : "je proclame, Junon Covella", il est dit sept fois : "je proclame, Junon Covella" » (trad. P. Flobert, Paris, CUF, 1985). ID., La langue latine, V, 13 : « et la curie Calabra [curie aux proclamations] ne saurait s'expliquer sans calatio [proclamation] ». Macrobe, Saturnales, I, 15, 11 : « Or, calo est un verbe signifiant "appeler" et le jour qui se trouvait en tête des jours que l'on appelait, on décida de lu donner le nom de calendes. C'est aussi de là qu'est venu le nom de la curie dite Calabre, près de laquelle se faisait l'appel » (trad. Ch. Guittard, Paris, Les Belles Lettres, 1997). Servius, Commentaire sur l'Énéide de Virgile, VIII, 654 (voir aussi infra n. 92) : « Et on a le mot "Calabra" pour la raison suivante : comme les calendes ou les ides étaient de date incertaine, il fut institué par Romulus que les patres ou le populus y soient "appelés" (calarentur), c'est-à-dire convoqués, afin qu'ils sachent quel jour il y aura les calendes ou aussi quel jour il y aura les ides. Le même procédé était effectué par le roi des sacrifices (rex sacrificulus), parce que les fastes [le calendrier publié] n'existaient pas encore, de manière à ce que les gens connaissent à l'avance les jours des jeux (ludi) et ceux des sacrifices ». Sur l'étroit lien étymologique et sémantique entre les termes calator, comitia calata, calendae et curia Calabra, voir notamment RüPKE, 1995, p. 212-216.

[90] Varron, La langue latine, VI, 28 : « Les Nones portent ce nom soit parce qu'elles tombent toujours le neuvième jour avant les Ides, soit parce que, au même titre que les Calendes de janvier sont appelées "nouvel $a^{\prime \prime}$ (novus annus) à cause du soleil nouveau ( $a b$ novo sole), les Nones sont appelées "nouveau mois" (novus mensis) à cause de la nouvelle lune. Ce même jour, le peuple venait de la campagne à la ville pour se rassembler auprès du roi (rex). Des traces de cet usage apparaissent dans les rites des Nones, sur l'Arx, parce que le roi (rex) annonce alors au peuple les premières fêtes mensuelles qui auront lieu ce mois-là » (trad. P. Flobert, Paris, CUF, 1985). Cf. Macrobe, Saturnales, I, 15, 12.

[91] Varron, La langue latine, V, $47:$ : (...) quant au mot Carinae, il vient peut-être de caerimonia (solennité religieuse) : car là commence la Sacra via (voie Sacrée), qui conduit du petit temple de Strenia à la citadelle (arx), c'est par cette voie qu'on porte les offrandes (sacra) à la citadelle tous les mois, et les augures, partis de la citadelle, ont I'habitude d'y procéder à des inaugurations. De cette Sacra via, la seule partie couramment bien connue <sous ce nom> est celle qui correspond à la première rampe 
dans I'area Capitolina, comme le soutient F. Coarelli, mais sur l'Arx où se tenaient les sacra Nonalia et où devait se trouver, dès l'époque archaïque, un lieu de culte consacré à Junon [92].

Le mois lunaire ne comptant que 29 jours environ, chaque mois, lors des sacra Nonalia, le rex (sacrorum) devait annoncer, au peuple convoqué aux comitia calata, le jour intercalaire ajouté au mois, de manière à aligner l'année lunaire à l'année solaire et à faire du calendrier romain un calendrier luni-solaire [93]. Dans le calendrier primitif, I'année commençait aux calendes de mars, mais se terminait le jour des Terminalia (le 23 février dans les calendriers préjulien et julien) [94] : le mois lunaire comptant 29 jours, il suffisait d'ajouter un jour intercalaire à chaque mois pour faire des Terminalia le $360^{e}$ jour de l'année. Dans ce cas, les cinq jours manquants devaient correspondre aux cinq jours « épagomènes » placés entre la fin de l'année, aux Terminalia, et le commencement de I'année suivante, aux calendes de mars [95]. Ces cinq jours surnuméraires n'appartenaient ni au mois de février, ni au mois de mars, et se trouvaient en quelque sorte hors du temps, ce qui obligeait le « roi » à se retirer de la cité pendant toute la durée de ce temps mort : cette fuite rituelle du « roi » avait lieu le lendemain des Terminalia, le jour du Regifugium (24 février du calendrier préjulien $=6^{e}$ jour avant les calendes de mars [96]), lorsque le « roi » quittait précipitamment le Comitium après y avoir accompli un sacrifice [97]. Il revenait ensuite avec le début de la nouvelle année, aux calendes de mars : ce jour-là, pour quand on vient du Forum » (trad. d'après J. Collart, Paris, 1954). Festus, p. 372 L., s.v. Sacram viam : « Certains pensent que la Sacra via est ainsi appelée parce que c'est là qu'aurait été conclu le traité entre Romulus et Tatius ; selon d'autres, ce nom lui serait venu de ce que les prêtres y passent pour aller accomplir les sacrifices relatifs aux Ides (idulia sacra). Il ne faut donc pas, comme le commun des hommes le suppose, l'appeler Sacrée depuis la Regia jusqu'à la maison du roi des sacrifices (domus regis sacrificuli), mais aussi depuis la maison du roi jusqu'au petit sanctuaire (sacellum) de Strenia, et encore depuis la Regia jusqu'à la citadelle (arx) ». Voir CoARelLI 1986, p. 50-56.

[92] Cf. CoArelli 1993, qui s'appuie sur le témoignage de Macrobe (supra n. 88) évoquant la proximité de la curia Calabra avec la casa Romuli, qu'on situe dans I'area Capitolina, à côté du temple de Fides. Mais le rapprochement proposé par Macrobe entre la curia Calabra et la casa Romuli est douteux, et provient peut-être d'une confusion avec la tradition qui attribuait à Romulus la couverture de la curia Calabra par un toit de chaume (Servius, Commentaire sur l'Énéide de Virgile, VIII, 654 : «On appelle curie Calabra celle que Romulus construisit avec un toit de chaume ») ; Macrobe a aussi pu effectuer ce rapprochement parce que, les comices calates, comme les comices curiates avec lesquels ils sont souvent confondus, étant censés avoir été établis par Romulus (Paul Diacre, Extraits tirés de Festus, p. 42 L.), il pensait qu'ils ne pouvaient se réunir qu'à proximité de la casa Romuli au Capitole, où se réunissait parfois le concilium plebis pendant la période républicaine (TiteLive, XXV , 3, 14 ; Appien, Guerre civile, I, 24-25), et aussi tout simplement parce que sa source englobait peut-être déjà l'Arx dans le Capitolium ; I'étroit rapport sémantique entre les termes calator, comitia calata, calendae, curia Calabra, ainsi que les témoignages de Varron et de Festus (supra n. 91) sur les cérémonies effectuées par les augures et les prêtres qui se rendaient chaque mois in arcem pour y accomplir des sacra, incitent à situer la curia Calabra plutôt sur l'Arx, dans le prolongement naturel de la via Sacra et des gradus Monetae ou centum gradus (futures scalae Gemoniae) (cf. aussi RüPKE 1995, p. 209-217). Sur la présence probable in arce d'un lieu de culte dédié à Junon à l'époque archaïque, antérieurement au temple de Junon Moneta dédié en 345/344 av. J.-C., voir COARELLI 1986, p. 104-106 ; et surtout GianelLi 1996.

[93] Voir supra n. 90 ; cf. Varron, La langue latine, VI, 13 : «Quand le roi des sacrifices proclame les fêtes du mois aux Nones de février, il appelle ce jour februatus » (trad. P. Flobert, Paris, CUF, 1985). Sur l'intercalation de jours supplémentaires, voir aussi : Tite-Live, I, 19, 6-7 (même si, dans le récit livien, cette intercalation concerne surtout le calendrier numaïque, c'est-à-dire le calendrier républicain préjulien).

[94] Varron, La langue latine, VI, 13 : « On dit Terminalia, parce que ce jour a été établi comme le dernier de l'année ; en effet, février a commencé par être le douzième mois et quand on intercale le mois supplémentaire, on retranche du douzième mois les cinq jours qui le terminent ». Ovide, Fastes, II, 47-50 : «En outre, comme vous pourriez faire erreur, faute de connaître l'ordre ancien des mois, sachez que celui de Janus, aujourd'hui le premier, l'était aussi jadis ; celui qui suit Janus était le dernier de l'année antique ; toi aussi, Terminus, tu marquais la fin des fêtes religieuses » (trad. H. Le Bonniec, Paris, Les Belles Lettres, 1990). Saint-Augustin, La cité de Dieu, VII, 7 : «Pourquoi donc dit-on que le commencement des choses est du domaine de Janus, mais leur achèvement de celui d'un autre appelé Terminus ? Car on assure que c'est à cause des commencements et des achèvements que deux mois ont été consacrés à ces dieux, en sus des dix mois qui vont de mars à décembre, à savoir janvier consacré à Janus, février consacré à Terminus ; et c'est la raison pour laquelle, dit-on, les Terminalia se célèbrent en ce même mois de février lors de la purification sacrée qu'on appelle Februm et d'où le mois a reçu son nom ». Voir aussi supra n. 83.

[95] MAGDELAIN 1990a.

[96] C'est ce jour (le 6e jour avant les calendes de mars) qui sera dédoublé pour les années « bissextiles 》 (ante diem bis sextum Kalendas Martias) dans le nouveau calendrier (julien) mis en place par Jules César en 46 av. J.-C. : César assumait ainsi le rôle que jouait le grand pontife dans l'établissement du calendrier civique et religieux, héritier lointain du rôle jadis joué par le « roi », c'est-àdire par le prêtre initialement le plus important du collège « pontifical », véritable « calendrier vivant » de la cité : RüPKE 1995, p. 369-391; ID. 2011, p. 109-121.

[97] Plutarque, Questions Romaines, 63 (Mor., 279 D) :

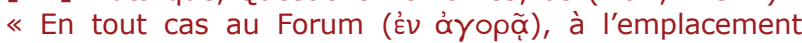
qu'on appelle Comitium ( un sacrifice ancestral que le roi accomplit et après lequel il s'enfuit aussi vite que possible du Forum ». Cf. Festus, p. 346 L. : <Regifugium dies notatur in fastis a. d.> VI Kal<alendas Martias dict>us quia <eo die rex Tarquinius fugerit e Roma> .... quod fal ....... Ovide, Fastes, II, 685-852 ; voir Fasti Antiates Maiores, InscrIt XIII, 2, p. $415-416$. 


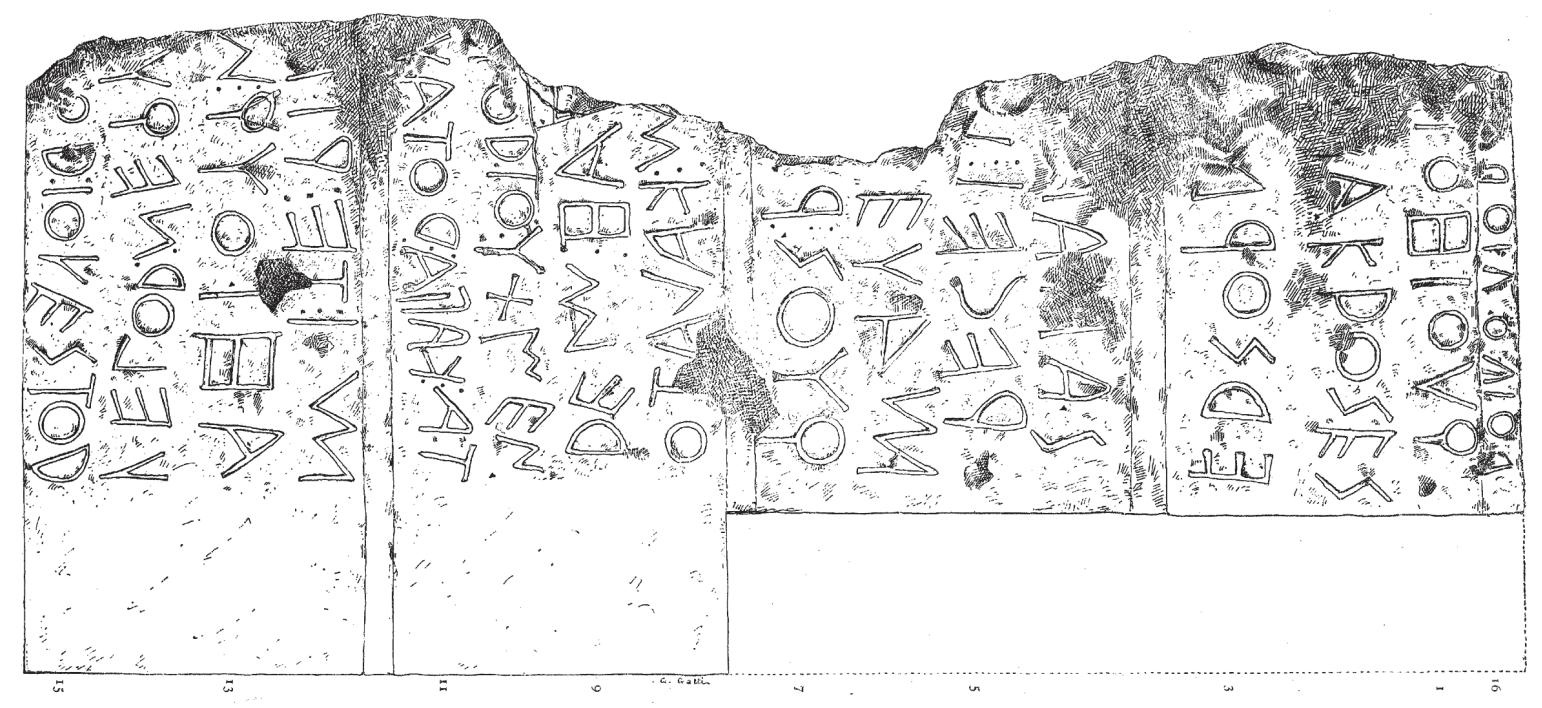

Figure 7 : inscription du cippe du Lapis Niger (apographe dans STEFFENS 1910, pl. 1).

marquer son retour, deux lauriers étaient disposés à la porte de la Regia [98]. A. Magdelain a brillamment montré que l'exclusion rituelle du « roi » pendant ces cinq jours « épagomènes » explique la durée et la procédure de l'interrègne (interregnum) pratiqué pendant la période républicaine pour organiser des élections consulaires en cas de disparition simultanée des deux consuls annuels : avant de devenir ce magistrat extraordinaire, I'interrex choisi parmi les patres avait la charge sacrale de remplacer le rex pendant ses cinq jours d'absence [99]. Ce fonctionnement archaïque du plus ancien calendrier romain, organisé autour de la personne du prêtre « roi », a probablement perduré jusqu'à la fin du IV siècle, et la seule « innovation républicaine » dans le déroulement des opérations de calendrier décrites par Macrobe a sans doute été « le rôle accru du pontife <mineur> à la place du calator ou héraut qui accompagnait le roi pour annoncer à voix haute ses ordres »[100].

On a précisément un témoignage épigraphique du $\mathrm{VI}^{\mathrm{e}}$ siècle qui mentionne ensemble le rex et le calator au Comitium : c'est I'inscription du cippe dit du Lapis Niger (fig. 7).

[98] Ovide, Fastes, III, 139 : «c'est alors qu'à la porte du roi <des sacrifices> (ianua regis) verdoie l'arbre de Phébus qu'on vient d'y placer » (trad. H. Le Bonniec, Paris, Les Belles Lettres, 1990). Macrobe, Saturnales, I, 12, 6 : «De plus, le premier jour de ce mois, on ranimait le feu sur les autels de Vesta, pour qu'avec le renouvellement de l'année, se renouvelât le soin d'entretenir le feu ravivé. Toujours au début du même mois, à la Regia, dans les curies et les maisons des flamines, on remplaçait les anciennes guirlandes de laurier par de nouveaux rameaux » (trad. Ch. Guittard, Paris, Les Belles Lettres, 1997). Voir BIANCHI 2010, p. 192-193.

[99] MagdeLAin 1990b.
1 - quoi hon[ce |...] sakros es|ed sord[es]

2 - ]ia has | recei io[... ....] euam | quos re[...]

3 - ]m kalato|rem ha[...]/tod iouxmen|ta kapia dotau[r...]

4 - ]am iter pe[... ...]m quoi ha|uelod nequ[...]|iod iouuestod

\section{5 - loi[u]quiod qo[...]}

D'après ILLRP 3 (cf. CIL I ${ }^{2} 1=$ CIL VI 36840).

Quel que soit le sens général de ce texte largement débattu, le mot rex y est exprimé au datif (RECEI) sur la $2^{\mathrm{e}}$ face (ligne 5 ), ce qui indique qu'une action était conférée ou attribuée au « roi »[101]; sur la $3^{e}$ face (ligne 8 ), on lit CALATOREM qui est généralement compris comme I'accusatif de calator, ce qui ferait de celui-ci l'objet d'une action, à moins qu'il ne faille lire, comme l'a proposé F. Coarelli, CALATOR EM HAB[ETOD...] où EM correspondrait à une forme archaïque de pronom, ce qui ferait du calator le sujet d'une action [102] ; enfin, il n'est pas impossible, selon certains, que le mot rex apparaisse une seconde fois dans le texte, à la fin de la $2^{\mathrm{e}}$ face (ligne 7), et cette fois au nominatif, ce qui en ferait aussi l'auteur d'une action [103]. Les premiers mots de l'inscription (SAKROS ESED) indiquent qu'il

[100] HeuRgon 1969, p. 204. Selon certains, le pontifex minor aurait en fait été un scribe du rex sacrorum, peutêtre élevé à ce rang lorsque les pontifes, à commencer par le pontifex maximus, commencèrent à prendre de l'importance au sein du futur collège « pontifical » : RüPKE 1995, p. 211 ; BIANCHI 2010, p. 196.

[101] WaChTER 1987, p. 66-69; Coarelu 1986, p. $179 ;$ ID. 2012, p. 98 ; BiANCHI 2010, p. 12-14 ; SANTORO 2016, p. 26.

[102] Coarelli 1986, p. 181-182 ; ID. 2012, p. 99.

[103] Coarelli 1986, p. 179-180; Bianchi 2010, p. 12. 
pourrait s'agir d'une lex sacra ; le texte prescrirait les précautions à prendre pour éviter que, lorsque le « roi » se rendait au Comitium, un « auspice d'attelage » (iuge[s] auspicium), particulièrement défavorable, ne contrarie la cérémonie qui s'y déroulait [104] ; les derniers mots lisibles (lignes 15-16) indiqueraient au contraire comment obtenir un « auspice favorable correctement pris » (auspicium iustum liquidum) [105]. Le calator qui y est mentionné est un « héraut » spécialement attaché à la personne du prêtre « roi » ou du rex sacrorum [106], et à l'époque historique, les calatores étaient encore attachés au collège des pontifes et des flamines, comme le révèle une inscription d'époque impériale retrouvée près de la Regia [107]. Parmi les activités que le « roi » pouvait mener au Comitium en compagnie d'un calator, nous savons qu'il se rendait sur cette place le 24 mars et le 24 mai, deux jours a priori « néfastes », pour y présider les comices calates (comitiare), ce qui avait pour effet de rendre ces jours «fastes » : ils étaient encore marqués, dans le calendrier républicain, par les lettres QRCF qui signifient Quando rex comitiavit, fas (« Lorsque le rex réunit les comices, ce jour devient faste ») [108]. Ces comices étaient appelés calates parce qu'ils étaient convoqués (calata) par le calator du prêtre « roi » (ou bien par celui des flamines, ou encore par celui des pontifes), et uniquement à des fins religieuses [109] : le rôle du calator était donc de comitia (calata) calare [110]. Autrement dit, les comices calates ne pouvaient être convoqués et présidés que par des prêtres publics issus du collège pontifical, afin de porter à la connaissance de la population un certain nombre d'annonces concernant la religion, ses rites ou son calendrier [111]. Les 24 mars et 24 mai, marqués QRCF, doivent correspondre aux deux jours où, selon le juriste Gaius, on convoquait jadis les comices calates pour établir
[104] Cf. Cicéron, De la divination, II, 77 ; voir DumÉZIL 1974, p. 99-103 ; HEURGON 1969, p. 205-206 ; SMITH 1996 , p. $167-169$; LOICQ 2004 , p. $234-236$; SANTORO 2016 , p. $36-38$

[105] Cf. Plaute, Epidicus, 181-183/184; Persa, 606-607; Pseudolus, 761-762; voir DumÉZIL 1979, p. 269, qui propose la restitution suivante des lignes 15 et 16 : auguri/om agese auispec]IŌD IOVESTŌD/LOI[V] QVI <D>ŌD, C'est-à-dire : auguri/um agere auspicio iusto liquido.

[106] Palmer 1969, p. 2 ; Beek 2012, p. 20-21. Cf. Paul Diacre, Extraits tirés de Festus, p. 34 L. : « Calatores, nom donné à des esclaves, du grec $k \alpha \lambda \varepsilon i ̃ v$ qui signifie appeler, parce qu'on peut les appeler à tout instant en raison des obligations liées à la servitude ». Servius Daniel, Commentaires sur les Géorgiques de Virgile, I, 268 : " "Oui certes, même certains jours de fête, <i y a des jours où il est religieusement permis (faste) de travailler>" (QUIPPE ETIAM FESTIS q[uaedam] e[xercere] $d[$ iebus]) : (...). Il y a en effet des travaux qui, s'ils sont accomplis les jours de fête, profanent les fêtes religieuses (féries) : c'est pourquoi les pontifes ont coutume de demander à leurs calatores d'annoncer à l'avance qu'ils vont procéder à un sacrifice (...) 》.

[107] CIL VI 31426 = VI $37167:$ [In h]onorem domus Aug(ustae) kalatores pontificum et flaminum. Avec d'autres inscriptions retrouvées sur place, on y a vu la preuve de l'existence à cet endroit d'un siège officiel des calatores (ou Schola kalatorum) : COARELLI 1986, p. 181 ; SMITH 1996, p. 169 ; Scott 1999b ; cf. Van Haeperen 2002, p. 82 et p. 337-339.

[108] Fasti Antiates Maiores, InscrIt XIII, 2, 1, p. 7 (24 mars) : $q$ (uando) $r(e x) c(o m i t i a v i t), f(a s)$. Fasti Praenestini, InscrIt XIII, 2, 17, p. 122-123 (24 mars) : C VIIII [q(uando) r(ex)] c(omitiavit) $f(a s)$. Hunc diem plerique perperam / int[e]rpr[e]tantes putant appellari, / quod eo die ex Comitio fugerit / [rex; n]am neque Tarquinius abiit ex Comitio / [in exilium] et alio quoque mense eadem sunt / [idemque s]ignificant. Qu[are sacris peractis] / [iudici]a fi[e]ri indica[ri iis magis putamus] (Jour $\mathrm{C}=9^{\mathrm{e}}<$ jour avant les calendes d'avril $>$, quand le roi réunit les comices, le jour devient faste [QRCF]. La plupart des gens pensent, en interprétant <ces lettres> de travers, que ce jour est ainsi appelé parce que le roi fuierait du Comitium ce jour-là ; car Tarquin ne partit pas en exil en quittant le Comitium, et les mêmes lettres [QRCF] existent aussi pour un autre mois où elles signifient la même chose. C'est pourquoi nous pensons plutôt qu'elles indiquent que des rites sacrés (sacra) ainsi que des actions judiciaires (iudicia) peuvent être accomplis <ce jour-là> »; cf. Varron, La langue latine, VI, 31 ; Ovide, Fastes, V, 727-728 ; Paul Diacre, Extraits tirés de Festus, p. 311 L., s.v. Quando rex comitiavit fas. Le rapprochement entre le texte de l'inscription du Lapis Niger et le rituel des 24 mars et 24 mai a déjà été proposé par CoARelli 1986, p. 186-188; ID. 2012, p. 96-98.

[109] En-dehors de l'annonce du calendrier aux calendes et aux nones, les comices calates étaient également convoqués pour l'inauguratio regis et flaminum (maiorum), l'adrogatio d'un individu aboutissant à la detestatio sacrorum, à la transitio ad plebem ou à la cooptatio in patres, et la confection des testaments : Kübler 1897 ; Pina Polo 1989, p. 54-64 ; Smith 1996, p. $169-170$; BIANCHI 2010 , p. 201-205.

[110] Coarelli 1986, p. 180 ; SMith 1996, p. 169.

[111] Laelius Felix, fr. 1 Huschke (chez Aulu-Gelle, Nuits attiques, XV, 27, 1-3) : «Dans le premier livre du commentaire de Laelius Felix à Quintus Mucius, il est écrit que, suivant Labéon, les comices calates sont ceux qui ont lieu devant le collège des pontifes ou le roi ou les flamines pour procéder à des inaugurations. Parmi les comices, les uns sont curiates, d'autres centuriates; les comices curiates "sont appelées" (calari), c'est-à-dire convoqués (convocari), par le licteur curiate, <tandis que> les comices centuriates <sont convoqués> par le sonneur de cor. Aux même comices que nous avons dit s'appeler calates on faisait et la renonciation au culte $<$ familial>, et les testaments. Il y avait en effet trois genres de testaments, avons-nous appris : les uns se faisaient aux comices calates devant une réunion du peuple, d'autres en tenue de campagne quand les hommes étaient appelés à monter en ligne pour livrer bataille, les troisièmes par emancipatio du bien de famille, <emancipatio > pour laquelle on utilisait le bronze et la balance » (trad. d'après R. Marache, Paris, CUF, 2002). 
les testaments sous la présidence du rex sacrorum (selon une procédure qu'il dit être ensuite tombée en désuétude) [112]. Ces jours étaient à chaque fois précédés du Tubilustrium, jour où I'on procédait à la purification des trompettes, ce qui était, comme I'établissement des testaments, une préparation à la saison guerrière [113].

\section{LE « ROI » ET LE POUVOIR POLITIQUE}

L'inscription du Lapis Niger est aujourd'hui sûrement datée du $\mathrm{vI}^{\mathrm{e}}$ siècle (voire même de la première moitié du $\mathrm{vI}^{\mathrm{e}}$ siècle) [114]. Le rex qui y est mentionné en compagnie d'un calator correspond en tout point au « roi » auquel nos sources attribuent des fonctions religieuses au Comitium, et doit être de même nature que le rex mentionné par le graffito sur la coupe en bucchero de la Regia [115]: il ne peut donc pas s'agir d'un rex optimo iure, c'est-à-dire du chef politique et militaire de Rome [116], et encore moins de Romulus [117], mais d'un « roi-prêtre » en charge d'un certain nombre de rites sacrés depuis le cœur de la période royale jusqu'à l'époque médio-républicaine au moins [118]. Autrement dit, le rex sacrorum de la République romaine ne peut pas avoir été un prêtre créé ex nihilo en 509 pour remplacer le vrai roi en fuite, mais doit être le continuateur du prêtre portant le titre de « roi » qui officiait dans la Regia et sur le Comitium depuis au moins le début du $\mathrm{vI}^{\mathrm{e}}$ siècle (voire le dernier quart du $\mathrm{VII}^{\mathrm{e}}$ siècle si on tient compte de la stratigraphie de la Regia). Pour certains, le rex sacrorum ne serait qu'un « roi déchu», une sorte de fossile de la royauté (latine) primitive qui aurait vu ses fonctions se limiter au sacré dès l'époque archaïque, avec I'instauration de la monarchie étrusque [119] ; pour d'autres, ce serait un prêtre, à l'origine « obscur auxiliaire des temps royaux »[120]. On a aussi rapproché le rex sacrorum romain d'autres prêtres portant le titre de « roi » dans plusieurs cités latines comme Bovillae, Tusculum, Lanuvium ou Velletri, et naturellement du fameux rex Nemorensis attaché au sanctuaire de la Diane d'Aricie, mais la chronologie de l'existence de ces prêtres à l'époque archaïque est mal assurée [121]. T. J. Cornell s'est interrogé sur la nécessité qu'il y aurait eu à créer ex nihilo un rex sacrorum au début de la République, s'il a finalement été possible au pontifex maximus d'assumer les mêmes fonctions religieuses ; d'autre part, si les consuls ont pu assumer une partie des fonctions sacrées des rois (sacrifices publics, prises des auspices, vœux publics et dédicaces de temples), et que le grand pontife a pu prendre en charge les autres, on ne voit plus la nécessité de créer un rex sacrorum au moment de la fondation de la République : I'historien a fini par conclure que le rex sacrorum devait être entré en fonction avant le début de la République [122]. Si tel est le cas, Rome aurait eu, peut-être dès la fin du viI ${ }^{\mathrm{e}}$ siècle, une sorte de « roiprêtre » sans fonctions de gouvernement politique, mais qui aurait exercé des fonctions religieuses en rapport avec le temps et la sauvegarde de la communauté : il en symbolisait l'unité et en « réglait » l'accord avec l'ordre naturel du monde, suivant le sens qu'on peut donner aux mots latins regere ou rectus, d'où est tiré le titre de rex [123] ; il exerçait ses fonctions dans la Regia, bâtiment de fonction
[112] Gaius, Institutes, II, 101-103 ; Laelius Felix fr. 1 Huschke (supra n. 111) ; cf. Fasti Antiates Maiores, InscrIt XIII, 2, 1, p. 7 (supra n. 108). Voir BIANCHI 2010, p. 205-207.

[113] Varron, La langue latine, VI, 14 : « Le jour du Tubilustrium porte ce nom, parce que ce jour-là on purifie les trompettes des sacrifices (sacrorum tubae) dans I'Atrium Sutorium » (trad. P. Flobert, Paris, CUF, 1985). Voir MAGDELAIN 1990c.

[114] WACHTER 1987, p. 66-69; COARELli 1986, p. $177-188$; M. Cristofani, dans CRISTOFANI 1990, p. 58-59 ( $n^{\circ}$ 3.1.39) ; PallotTino 1993, p. 40 et p. 211-212 ; HolLoWAY 1994, p. 81-88.

[115] Sмітн 1996, p. 170-171.

[116] Sur l'expression rex optimo iure, voir Tite-Live, IX, 34, 12 (supra n. 47).

[117] Cf. Festus, p. 184 L. : Niger lapis in comitio locum funestum significat, ut ali, Romuli morti destinatum, sed non usu ob in [...] [Fau]stulum nutr[...] [Quinc]tilium avum tu[...] cuius familiae [...] tionem eius ( La pierre noire marque, au Comitium, un lieu funeste affecté, selon certains, à la mort de Romulus, mais il n'y fut point enseveli ; Faustulus, son père nourricier, y fut, dit-on, enseveli, ainsi que Quinctilius, aïeul de $(. .$.$) , dont la famille$ [Quinctilia] a été dénommée à partir de son nom ».

[ Cf. Coarelli 1999a ; Santoro 2016, p. 51-54.

[118] Stroux 1931, p. 473 ; LeIFER 1932, p. 51 ; LOICQ 2004, p. 234-236 ; BEEK 2012, p. 21-22.

[119] De Sanctis 1907, p. 400-401; De Francisci 1959, p. 727-732 ; cf. LINKE 1995, p. 149-150.

[120] LOICQ 2004, p. 223-241.

[121] Voir Rosenberg 1914a, col. 717-718; BIANCHI 2010, p. $43-70$ et p. 92-103.

[122] CORNELL 1995, p. 234-235 ; cf. déjà, dans le même sens, De SAnctis 1907, p. 401.

[123] Linke 1995, p. 49-52 ; cf. ERnOut \& Meillet 1959, s.v. « rectus», p. 566 ; s.v. « rex», p. 572-573; voir aussi supra la théorie de G. Dumézil sur l'origine du rex latin, héritier du *reg- indo-européen, dans le prolongement d'une tradition indo-européenne de sortes de « rois-prêtres ». 
et de représentation, au Comitium, lieu de réunion officielle de la communauté civique, ainsi qu'à la curia Calabra et à l'auguraculum de l'Arx, sur un axe que reliait la via Sacra (supra fig. 6) depuis que Rome existait en tant que cité.

Le « roi-prêtre » de l'époque royale doit être distingué du chef politique et militaire de la cité pour plusieurs raisons. Il devait d'abord obligatoirement être un patricien (marié par confarreatio) [124], comme d'ailleurs les autres membres du collège pontifical sur lesquels il a longtemps eu une suprématie, alors que la tradition annalistique est unanime à penser que les souverains étrusques qui dirigeaient Rome à l'époque archaïque, au temps des Tarquins, non seulement n'étaient pas patriciens, mais se seraient régulièrement opposés politiquement aux patriciens [125]. D'ailleurs, il n'est même pas certain que les cités étrusques du $\mathrm{VI}^{\mathrm{e}}$ siècle aient véritablement connu des « rois » (au sens de monarques politiques et militaires) [126] : sur les lamelles d'or de Pyrgi, si Thefarie Velianas est défini $m / k$ (« roi ») dans le texte punique, il est appelé zilath (« magistrat ») dans le texte étrusque [127]. De même, on peut légitimement se demander si les Tarquins et Servius Tullius, que la tradition annalistique romaine fait « régner » entre la fin du vII ${ }^{\mathrm{e}}$ siècle et la fin du $\mathrm{VI}^{\mathrm{e}}$, étaient véritablement des « rois » : en conformité avec le contexte politique méditerranéen du $\mathrm{VI}^{\mathrm{e}}$ siècle, ils semblent plutôt avoir été des «tyrans », et sur le plan institutionnel, leur fonction correspondrait plutôt à celle du magister populi qui préfigura la dictature républicaine [128]. En fait, la tradition annalistique romaine, mais aussi les sources étrusques évoquées par l'empereur Claude dans son discours au Sénat ainsi que les fresques

[124] Cicéron, Sur sa maison, 38 ; Tite-Live, VI, 41, 9 ; voir Rosenberg 1914b, col. 723 ; BiAnCHI 2010, p. 131-135.

[125] LoICQ 2004, p. 231 ; SмIтH 2011, p. 39.

[126] Briquel 1987, p. 139-148; LoICQ 2004, p. 226-229; BARTOLONI 2009.

[127] CIE 6314 et 6315 (TLE 873 et 874) ; PalLotTino 1984 , p. 445-446 ; BIANCHI 2010, p. 74-75.

[128] LOICQ 2004, p. 229-232.

[129] LoICQ 2004, p. 229-232; SмIтH 2011, p. 39 ; HUMм 2017.

[130] De Francisci 1959, p. 727-732.

[131] Denys d'Halicarnasse, Antiquités Romaines, IV 74, 4 (voir supra n. 9) ; V, 1, 4 : « Cependant, comme il apparaissait que les rois avaient été à l'origine de nombreux et grands avantages pour la communauté, ils désirèrent conserver le nom de cette charge aussi longtemps que la cité existerait, et ordonnèrent aux pontifes et aux augures (Toùs i de la tombe François de Vulci, suggèrent clairement que ces souverains étaient avant tout des chefs de guerre et des condottieri dont les activités guerrières étaient proprement incompatibles avec les nombreuses contraintes rituelles qui pesaient sur le « roi-prêtre » romain tout au long de l'année [129]. Inversement, le statut très particulier du rex sacrorum rendait sa fonction totalement incompatible avec les activités guerrières, puisqu'il lui était formellement interdit, pendant toute la période républicaine, d'exercer la moindre magistrature [130]: cette interdiction absolue, qui explique les réticences manifestées par certains aristocrates patriciens à exercer cette fonction, et explique probablement aussi son déclin, était justifiée selon les auteurs romains par la volonté de garantir la libertas républicaine et d'empêcher un éventuel retour à la royauté [131]. Parallèlement, Tite-Live explique que si I'on fait commencer la libertas en 509 , « cela tient plus au fait que le pouvoir de commandement consulaire (imperium consulare) devint annuel qu'au fait qu'on aurait diminué en quoi que ce soit la puissance royale (regia potestas) » [132]. Autrement dit, le rex sacrorum et le consul se distinguent par la spécialisation de leurs fonctions respectives : I'un dans les fonctions exclusivement religieuses, l'autre dans les fonctions politiques et militaires. On retrouve en fait, dans cette distinction entre fonction religieuse et fonction politique, la « séparation très nette entre prêtre et magistrat » déjà soulignée à plusieurs reprises par J. Scheid, une séparation qui reflète la dichotomie entre celui qui est chargé de négocier avec les dieux et celui qui est chargé d'agir avec les hommes [133]. On peut légitimement penser qu'une telle dichotomie est en

de choisir parmi les anciens celui qui conviendrait le mieux pour cette fonction; celui-ci devra uniquement s'occuper des cultes rendus aux dieux et de rien d'autre, étant exempté de toute fonction militaire et politique,

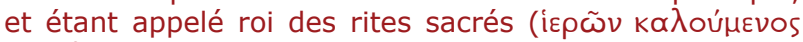

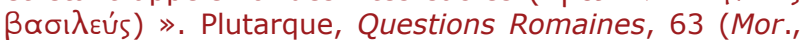
279 D) : « Les Romains, après avoir entièrement chassé leurs rois, en ont institué un autre pour accomplir les


interdit d'exercer une magistrature ou de parler devant le peuple, afin qu'ils paraissent être soumis à des rois uniquement dans le cadre des rites sacrés et ne suppor-

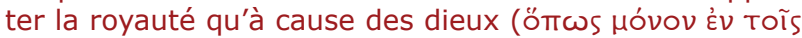

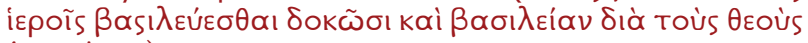

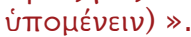

[132] Tite-Live, II, 1, 7 : Libertatis autem originem inde magis quia annuum imperium consulare factum est quam quod deminutum quicquam sit ex regia potestate numeres.

[133] SCHEID 1984 ; ID. 2001, p. 65-69 ; ID. 1992, p. $97-104$. 
quelque sorte structurelle à Rome et qu'elle préexistait à la République : autrement dit, si les consuls ont repris le pouvoir politique et militaire des chefs qui gouvernaient à l'époque archaïque, alors le rex sacrorum n'est que le prolongement du « roiprêtre » qui avait la haute main sur les fonctions religieuses de la communauté à l'époque prétendument « royale» [134].

Par conséquent, la reconstruction de la Regia pour la cinquième fois vers la fin $\mathrm{du}_{\mathrm{VI}}^{\mathrm{e}}$ siècle, au moment du départ du dernier Tarquin, ne s'explique pas par la création du rex sacrorum, c'està-dire d'un prêtre spécifique censé remplacer dans ses fonctions religieuses le vrai « roi » qui venait de partir. Cette substitution est en effet impossible car le « roi-prêtre » existe peut-être depuis les origines de la cité à Rome, en tout cas probablement au moins depuis le début de la domination étrusque sur la ville, à partir du dernier quart du $\mathrm{VII}^{\mathrm{e}}$ siècle (première phase de la Regia). Elle est également impossible parce qu'à cette époque au moins, les « rois » optimo iure, au sens politique de monarques, n'ont pas existé : les souverains romains de l'époque archaïque étaient en fait des condottieri et des «tyrans», des seigneurs de la guerre davantage préoccupés par leurs opérations militaires que par les rituels religieux contraignants que pratiquait le « roi-prêtre » à la Regia et au Comitium. Dans ce cas, les quatre premières phases de construction de la Regia à l'époque archaïque pourraient effectivement s'expliquer par les variations qu'a connu le pouvoir politique à Rome entre la fin du vir ${ }^{e}$ siècle et la fin du $\mathrm{VI}^{\mathrm{e}}$, si le « roi-prêtre » qui y officiait n'était qu'un représentant du pouvoir politique (ou son « auxiliaire » religieux). C'est ce que peuvent suggérer les diverses interprétations qui sont faites aujourd'hui du thème iconographique du « Minotaure » qui apparaît sur des plaques décoratives en terre cuite de la Regia $3^{\mathrm{e}}$ phase, vers 570 av. J.-C. (fig. 8) [135]. F.-H. Massa Pairault remarque que la représentation du Minotaure tué par Thésée apparaît sur divers objets en céramique retrouvés en Étrurie à partir du début $d u \mathrm{VI}^{\mathrm{e}}$ siècle, et interprète par conséquent sa présence sur les murs contemporains de la Regia comme un motif symbolique associé au pouvoir politique de type tyrannique qui tendait alors à se substituer à l'ancien pouvoir royal [136]. Le « Minotaure » de la Regia de Rome (comme d'ailleurs celui de la Regia de Gabies, découvert récemment [137]) n'est toutefois pas représenté dans son face-à-face mortel avec Thésée, et semble davantage figurer une force triomphante. C. Ampolo avait rapproché sa représentation sur les murs de la Regia de celle parmi les enseignes des légions, avant que Marius n'imposât la figure de l'aigle [138] : le Minotaure aurait donc primitivement été un symbole de force militaire, et sa présence à la Regia pourrait s'expliquer par celle du sacrarium de Mars et par la fonction guerrière symbolique du « roi-prêtre »[139]. Bien plus, suivant une interprétation déjà proposée par P. Romanelli, puis reprise et développée par M. Menichetti, la figure triomphante du « Minotaure », que I'on voit accompagné de félins (panthères ou lionnes) et d'un oiseau (grue ou autruche), serait en fait une représentation de Dionysos à tête de taureau, en rapport avec le thème du triomphe royal à l'époque archaïque (et de ses origines dionysiaques [140]),
[134] Voir SMITH 2011, p. 41-42.

[135] Romanelli 1955 ; GJerstad 1960, p. 287-288 et fig. 189 ; ID. 1966 , p. 474-476 et fig. 141-142; VERZÁR 1980 , p. $46-47$; S. B. Downey, dans StOPPoni 1985, p. $188-189$; CRISTOFANi 1987 ; S. Panella, dans CRIStOFani 1990, p. 60-61 (3.11, 3.13 et 3.14) ; DoWney 1993, p. 235-236 ; RYSTEDT 1993 ; MeNICHETTI 1994, p. 105-106 et p. $109-113$; SCODELLARI 2004, p. 181-187 ; LOSEHAND 2007, p. 74-82.

[136] Massa-Pairault 1992, p. 43-45 ; cf. Coarelli 2011, p. 61-64, pour qui la scène du Minotaure accompagné d'une série de félins et de grues est « indissociable du mythe athénien de Thésée » et «traduit la personnalité idéale du roi, dans sa dimension d'apothéose ».

[137] Des fouilles archéologiques menées à Gabies par la Surintendance archéologique du Latium ont récemment mis au jour une nouvelle représentation du Minotaure sur une plaque en terre cuite, très semblable à celle de la Regia de Rome, dans un bâtiment de la fin du vi ${ }^{\mathrm{e}}$ siècle dont le plan et la structure interne ressemblent très fortement à ceux de la Regia de Rome ; cette sorte de duplication de la Regia romaine pourrait s'expliquer par les liens politiques et religieux étroits que Rome entretenait avec cette cité latine à l'époque archaïque, particulièrement à l'époque de Tarquin le Superbe (cf. Tite-Live, I, 53, 4-11; 54, 1-10; 60, 2 ; Denys d'Halicarnasse, Antiquités Romaines, IV, 55-58 ; Plutarque, Romulus, 6, 1) : FABBRI, Musco \& OSANNA 2010 ; ID. 2012 ; voir aussi supra notre «Introduction » à ce dossier, p. 11 et fig. 2 et 3.

[138] Festus, p. 135 L., s.v. Minotauri effigies : « La représentation du Minotaure figure parmi les enseignes militaires, parce que les projets des généraux ne doivent pas être moins secrets que ne l'était le labyrinthe, le domicile de ce dernier ». Pline I'Ancien, Histoire naturelle, $X, 16$ : «Caius Marius, lors de son deuxième consulat [104 av. J.-C.], consacra l'aigle à titre exclusif aux légions romaines. Auparavant, il était au premier rang, mais avec quatre autres emblèmes : le loup, le minotaure, le cheval et le sanglier venaient chacun en tête d'une ligne » (trad. d'après S. Schmitt, Paris, « La Pléïade », 2013). Cf. Festus, p. 266 L. ; p. 267 L, s.v. Porci effigies.

[139] Ampolo 1990, p. 615-617 ; voir aussi Liou-Gille 2007, p. 69-76.

[140] Voir Нuмm 2017. 


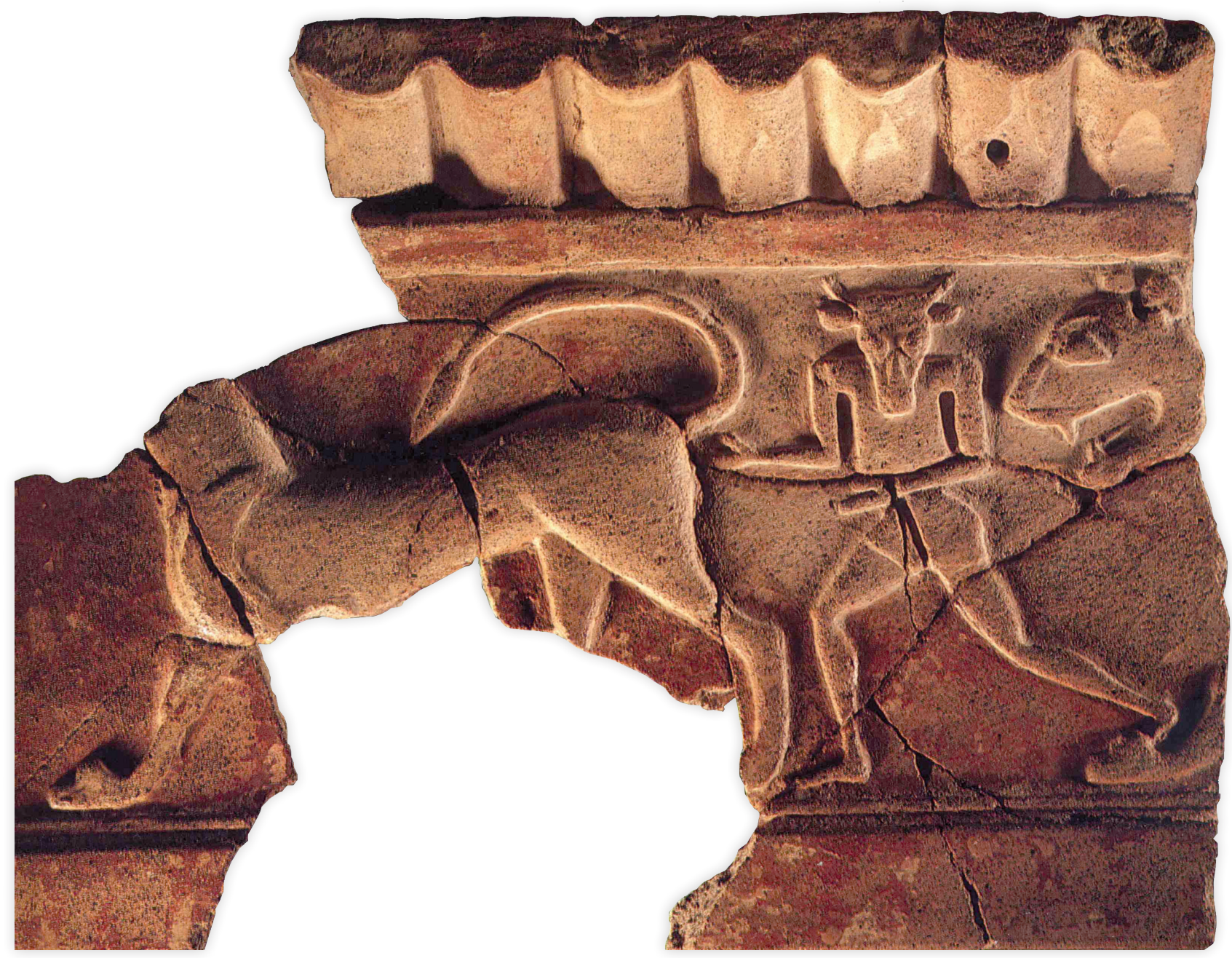

Figure 8

Le « Minotaure » sur une plaque en terre cuite de la Regia (CRISTOFANI 1990,

Tav. III, fig. 3.2.13, ( éditions « L’Erma » di Bretschneider, Rome).

d'autant que la Regia, située sur la via Sacra, est directement placée sur le parcours du triomphe et se trouve étroitement liée au rituel archaïque du Cheval d'octobre, lui-même en rapport avec le triomphe royal primitif [141]. Or la force militaire ainsi que le triomphe constituaient des éléments essentiels du pouvoir de type «tyrannique » exercé par les chefs de guerre qui dirigeaient les cités étrusques et latines au cours $d u v^{\mathrm{e}}$ siècle, si bien que l'apparition du thème iconographique du «Minotaure » sur les murs de la Regia vers 570, en lien avec une nouvelle phase architecturale du bâtiment, peut également être mise en rapport avec la prise de pouvoir d'un nouveau condottiere à la tête de la cité. Le « roi-prêtre » qui exerçait ses fonctions sacrées à l'intérieur de la Regia devait donc être étroitement associé, au moins au moment de sa nomination, au pouvoir politique de type militaire qui dirigeait la cité.
Si donc les quatre premières phases de la Regia s'expliquent par des changements politiques à la tête de I'État romain, la cinquième phase ne peut pas s'expliquer par la création d'une nouvelle fonction religieuse en lien avec le bâtiment, même si cette phase s'est «sclérosée » jusqu'à la fin de l'histoire de la Regia, au IV siècle ap. J.-C. La Regia a en effet toujours eu une fonction en rapport avec la religion et le temps de la cité, depuis ses origines les

[141] Romanelli 1955 ; Menichetti 1994, p. 109-113; cf. Coarelli 1986, p. 75-77 ; Losehand 2007, p. 74-82 (qui interprète ce Dionysos à tête de taureau comme un symbole divin d'abondance et de prospérité agricoles). Le thème du triomphe apparaît également sur la plaque (type A) décorant la regia d'Acquarossa et représentant Héraclès menant le taureau de Crète derrière un char triomphal tiré par des chevaux ailés : voir MeNICHETTI 1994, p. 98-100 ; voir aussi la contribution de D. Briquel dans ce dossier (fig. 10). 
plus lointaines jusqu'à la fin de son existence : elle est d'ailleurs définie par Festus comme un «sanctuaire »(fanum), et il y a peu de chance qu'elle n'ait jamais été autre chose [142]. Les différentes variations de son plan interne ne peuvent avoir eu aucune incidence sur l'organisation des rituels qui y étaient pratiqués et, surtout, ne signifient aucun changement dans sa fonctionnalité. La construction de la cinquième phase de la Regia ne se justifie donc pas plus par la création du rex sacrorum que les quatre premières phases. Il faut en réalité renverser les termes du problème : si les quatre premières phases s'expliquent par des changements du pouvoir politique à la tête de la cité, alors la cinquième phase s'explique pour la même raison, et le maintien de son organisation architecturale pendant les siècles suivants ne s'explique que parce que le prêtre public qui officiait dans la Regia (qu'il fût le rex sacrorum ou plus tard le pontifex maximus) n'était plus le partenaire religieux d'un pouvoir politique personnel et périodiquement renouvelé, mais celui de la res publica. Cette « sclérose » architecturale s'explique probablement aussi par le déclin institutionnel et religieux du rex sacrorum. En cela, la Regia est aussi bien le miroir de l'évolution politique et institutionnelle de la cité, que le reflet de ses structures civiques et religieuses les plus durables.

[142] Festus, p. 346-348 L., S.v. Regia : voir supra n. 5.

\section{BIBLIOGRAPHIE}

Ampolo, Carmine, 1971, « Analogie e rapporti fra Atene e Roma arcaica. Osservazioni sulla Regia, sul rex sacrorum e sul culto di Vesta », Parola del Passato 26, 1971, p. 443-460.

Ampolo, Carmine, 1990, « Roma e il mondo greco dal secolo viII agl'inizi del iII a.C. », dans Giovanni Pugliese Carratelli (éd.), Roma e I'Italia. Radices imperii, Milano, p. 583-626.

Bartoloni, Gilda, 2009, «The earliest Etruscan toast: considerations on the earliest phases of Populonia », dans Margareta Gleba \& Hilary Becker (éd.), Votives, places and rituals in Etruscan religion: essays in honor of Jean MacIntosh Turfa, Leiden - Boston (Religions in the Graeco-Roman World, 166), p. 157-170.

BaUdRY, Robinson, 2008, Les patriciens à la fin de la République romaine et au début de l'Empire, thèse de Doctorat, Université de Paris I Panthéon-Sorbonne.

Bauman, Richard Alexander, 1983, Lawyers in Roman Republican Politics. A study of the Roman jurists in their political setting, 316-82 BC, München.

Beard, Mary, North, John \& Price, Simon, 1998, Religions of Rome, vol. 2, A Sourcebook, Cambridge.

Befk, Leon ter, 2012, « Divine Law and the Penalty of sacer esto in Early Rome », dans Olga Tellegen-Couperus (éd.), Law and Religion in the Roman Republic, Leiden - Boston (Mnemosyne Supplements 336), p. 11-29.

Bendlin, Andreas, 2001, s. v. Rex sacrorum, Der Neue Pauly 10, col. 937-939.

BiANCHI, Edoardo, 2010, Il rex sacrorum a Roma e nell'Italia antica, Milano.

BREtone, Mario, 1997, Storia del diritto romano, Roma - Bari, 1997.

Briquel, Dominique, 1987, «La royauté en Étrurie. Les apports récents : confirmations et remises en cause », Ktèma 12, p. $139-148$.

Briquel, Dominique, 2000, «Les difficiles débuts de la liberté », dans François Hinard (éd.), Histoire romaine, Tome 1, Des origines à Auguste, Paris, p. 131-161.

Brown, Frank Edward, 1935, « The Regia », Memoirs of the American Academy in Rome 12, p. 67-88.

Brown, Frank Edward, 1967, « New soundings in the Regia: the evidence for the early Republic », dans Fondation Hardt pour l'étude de I'Antiquité classique (éd.), Les origines de la République romaine, Genève (Entretiens sur I'Antiquité classique 13), p. 47-60.

Brown, Frank Edward, 1974-1975, «La protostoria della Regia », Atti della Pontificia Accademia Romana di Archeologia, Série III, Rendiconti 47, p. 15-36.

Camous, Thierry, 2004, Le Roi et le fleuve. Ancus Marcius Rex aux origines de la puissance romaine, Paris.

Carandini, Andrea, 1997, La nascità di Roma. Dèi, lari, eroi e uomini all'alba di una civiltà, Torino.

Carandini, Andrea, 2010, Le case del potere nell'antica Roma (con Daniela Bruno e Fabiola Fraioli), Roma - Bari.

Carlier, Pierre, 1984, La royauté en Grèce avant Alexandre, Strasbourg.

Carnabuci, Elisabetta, 2012, Regia. Nuovi dati dagli appunti inediti di Giacomo Boni, Roma.

Castagnoli, Ferdinando, 1993, «Ibam forte via sacra (Hor., Sat. I. 9, 1) » [1988], dans Ferdinando Castagnoli, Topografia antica. Un metodo di studio, I, Roma, Roma.

Coarelli, Filippo, 1984, Roma sepolta, Roma. 


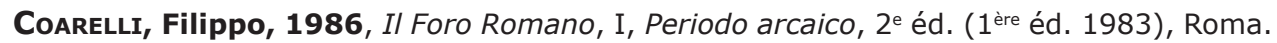

CoARelli, Filippo, 1993, s. v. Curia Calabra, Lexicon Topographicum Urbis Romae (LTUR), I (A-C), p. 330-331.

CoArelli, Filippo, 1999a, s. v. Sepulcrum Romuli, LTUR, IV (P-S), p. 295-296.

Coarelli, Filippo, 1999b, s. v. Strenia, sacellum, lucus, LTUR, IV (P-S), p. 378.

Coarelli, Filippo, 1999c, s. v. Vicus Vestae, LTUR, V (T-Z), p. 198-199.

Coarelli, Filippo, 2001, « Il sepolcro e la casa di Servio Tullio », Eutopia N. S. 1 (1-2), p. 7-43.

CoARelLi, Filippo, 2011, L'art romain des origines au III siècle av. J.-C., Paris, 2011.

CoARelli, Filippo, 2012, «Il "cippo del Foro" », dans Rosanna Friggeri, Maria Grazia Granino Cecere \& Gian Luca Gregori (éd.), Terme di Diocleziano. La collezione epigrafica, Milano, p. 95-99.

Cornell, Tim J., 1995, The Beginnings of Rome. Italy and Rome from the Bronze Age to the Punic Wars (c. 1000264 BC), London - New York.

Crawford, Michael H. (éd.), 1996, Roman statutes, London (Bulletin of the Institute of Classical Studies. Supplement 64), 2 vol..

CRIStofani, Mauro, 1987, «I santuari: tradizioni decorative», dans Mauro Cristofani (éd.), Etruria e Lazio arcaico: atti dell'Incontro di studio (10-11 novembre 1986), Roma (Quaderni del Centro di studio per l'archeologia etrusco-italica 15), p. 95-120.

Cristofani, Mauro (éd.), 1990, La grande Roma dei Tarquini, catalogo della mostra (Roma, Palazzo delle Esposizioni, 12 giugno - 30 settembre 1990), Roma.

D'IPpolito, Federico, 1985, « Das ius Flavianum und die lex Ogulnia », Zeitschrift der Savigny-Stiftung für Rechtsgeschichte. Romanistische Abteilung 102, p. 91-128.

D'IPPolito, Federico, 1986, Giuristi e sapienti in Roma arcaica, Roma - Bari.

De Francisci, Pietro, 1959, Primordia civitatis, Roma.

De Sanctis, Gaetano, 1907, Storia dei Romani, II, La conquista del primato in Italia, Torino.

Downey, Susan B., 1993, « Archaic architectural terracottas from the Regia », dans RYSTEDT \& WiKANDER 1993, p. 233-247.

DumÉzIL, Georges, 1942, Jupiter, Mars, Quirinus. Essai sur la conception indo-européenne de la société et sur les origines de Rome, Paris.

DumÉzIL, Georges, 1954, «Les cultes de la Regia, les trois fonctions et la triade Jupiter, Mars, Quirinus », Latomus 13, p. 129-139.

DumÉzil, Georges, 1958, L'idéologie tripartie des Indo-Européens, Bruxelles (coll. Latomus 31).

DumézIL, Georges, 1961, « Le sacrarium Opis dans la Regia », Revue des Études Latines 39, p. 257-261.

DumézIL, Georges, 1974, La religion romaine archaïque, avec un appendice sur la religion des Étrusques, $2^{\mathrm{e}}$ éd. (1 1̀̀re éd. 1966), Paris.

DumÉzIL, Georges, 1975, Fêtes romaines d'été et d'automne, Paris.

DumÉzIL, Georges, 1979, Mariages indoeuropéens. Quinze questions romaines, Paris.

Ernout, Alfred \& Meillet, Antoine, 1959, Dictionnaire étymologique de la langue latine. Histoire des mots, 4 e éd. (1 ère éd. 1932), Paris.

Eтcheto, Henri, 2003, « Cognomen et appartenance familiale dans l'aristocratie médio-républicaine : à propos de I'identité du consul patricien de 328 av. J.-C. », Athenaeum 91, p. 445-468.

Eтcheto, Henri, 2012, Les Scipions. Famille et pouvoir à Rome à l'époque médio-républicaine, Bordeaux.

Fabbri, Marco, Musco, Stefano \& Osanna, Massimo, 2010, « Sur les traces des Tarquins à Gabies. Une découverte exceptionnelle », dans Palais en Méditerranée, de Mycènes aux Tarquins, Dossiers d'Archéologie 339, p. 62-65.

Fabbri, Marco, Musco, Stefano \& Osanna, Massimo, 2012, « Nuove indagini al Santuario Orientale di Gabii », dans Elisa Marroni (éd.), Sacra Nominis Latini. I Santuari del Lazio arcaico e repubblicano. Atti del Convegno Internazionale (Roma, Palazzo Massimo, 19-21 febbraio 2009), Napoli, p. 229-242.

Flobert, Pierre, 1985, Varron, La langue latine, Livre VI, Paris (CUF).

GJeRSTAD, Einar, 1960, Early Rome, III, Fortifications, domestic architecture, sanctuaries, stratigraphic excavations, Lund.

Guerstad, Einar, 1966, Early Rome, IV, 1, Synthesis of Archaeological Evidence, Lund.

GuarduccI, Margherita, 1972, «L'epigrafe REX nella Regia del Foro Romano », Vestigia 17, p. 381-384.

Heurgon, Jacques, 1969, Rome et la Méditerranée occidentale jusqu'aux guerres puniques, Paris (Nouvelle Clio 7).

Holloway, R. Ross, 1994, The Archaeology of Early Rome and Latium, London - New York.

Humm, Michel, 2005, Appius Claudius Caecus. La République accomplie, Rome (Bibliothèque des Écoles françaises d'Athènes et de Rome 322).

Нuмm, Michel, 2017, « L’hellénisme de Tarquin Le Superbe », dans Patricia S. Lulof \& Christopher J. Smith (éd.), The Age of Tarquinius Superbus. Central Italy in the Late 6th Century (Proceedings of the Conference The Age of Tarquinius Superbus, A Paradigma Shift? Rome, 7-9 November 2013), Leuven, p. 27-38.

IACOPI, Irene, 1983, «Documentazione archeologica sulla Regia », dans Itala Dondero \& Patrizio Pensabene (éd.), Roma repubblicana tra il 509 e il 270 a.C., Roma (Archeologia e storia a Roma 1), p. 37-49.

KüBLER, Bernhard, 1897, s. v. Comitia calata, RE, III, col. 1330-1334.

LANFrANCHI, Thibault, 2013, « À propos de la carrière de Cn. Flavius », Mélanges de l'École française de Rome Antiquité, 125-1 [en ligne], URL : https://mefra.revues.org/1322

LATTE, Kurt, 1960, Römische Religionsgeschichte, München.

Leifer, Franz \& Goldmann, Emil, 1932, Zum Problem der Foruminschrift unter dem Lapis Niger. I. LeIfer, Franz, Zwei neuere Lösungsvorschläge (Graffunder und Stroux). II. GoLDMANN, Emil, Deutungsversuch, Leipzig (Klio, Beiheft XXVII, NF, Heft 14). 
LINKE, Bernhard, 1995, Von der Verwandtschaft zum Staat. Die Entstehung politischer Organisationsformen in der fruhrõmischen Geschichte, Stuttgart.

Liou-Gille, Bernadette, 2000, « Les Agonia, le rex sacrorum et l'organisation du calendrier », Euphrosyne 28, p. 41-60.

Liou-Gille, Bernadette, 2007, « Du Minotaure de la Regia aux enseignes romaines. Intégration à date ancienne d'un monstre légendaire exotique à l'armée romaine », Revue belge de philologie et d'histoire 85, p. 57-76.

LoicQ, Jean, 2004, «Le rex sacrorum : prêtre de la République ou roi déchu ? », dans Paul-Augustin Deproost \& Alain Meurant (éd.), Images d'origines. Origines d'une image. Hommages à Jacques Poucet, Louvain (Transversalités 4), p. 223-241.

LosEHAND, Joachim, 2007, Häuser für die Herrscher Roms und Athens? Überlegungen zu Funktion und Bedeutung von Gebäude F auf der Athener Agora und der Regia auf dem Forum Romanum, Hamburg (Schriftenreihe Antiquitates 42).

Magdelain, André, 1990a, « Cinq jours épagomènes à Rome ? » [1962-1963], dans Magdelain 1990d, p. 279-303.

Magdelain, André, 1990b, « Auspicia ad patres redeunt » [1964], dans MAGDELAIN 1990d, p. 341-383.

MAGdelain, André, 1990c, « Quando rex comitiavit fas » [1980], dans MAGDELAIN 1990d, p. 271-277.

Magdelain, André, 1990d, Jus, Imperium, Auctoritas. Études de droit romain, Rome (Collection de l'École française de Rome 133).

Magdelain, André, 1995, De la royauté et du droit de Romulus à Sabinus, Roma (Saggi di storia antica 8).

MARco Simón, Francisco, 1996, Flamen Dialis. El sacerdote de Júpiter en la religión romana, Madrid.

Martin, Paul Marius, 1994, L'idée de royauté à Rome, II, Haines de la royauté et séductions monarchiques (du IVe siècle av. J.-C. au principat augustéen), Clermont-Ferrand.

Massa-Pairault, Françoise-Hélène, 1992, Iconologia e politica nell'Italia antica. Roma, Lazio, Etruria dal VII al I secolo a.C., Milano (Biblioteca di Archeologia 18).

Mekacher, Nina \& Van Haeperen, Françoise, 2003, « Le choix des vestales, miroir d'une société en évolution (III siècle a. C. - Ir siècle p. C.) », Revue de l'histoire des religions 220, p. 68-80.

Menichetti, Mauro, 1994, Archeologia del potere. Re, immagini e miti a Roma e in Etruria in età arcaica, Milano (Biblioteca di Archeologia, 21).

Michels, Agnes Kirsopp, 1967, The calendar of the Roman republic, Princeton.

Momigliano, Arnaldo, 1969, «Il rex sacrorum e I'origine della Repubblica » [1969], dans Quarto contributo alla storia degli studi classici e del mondo antico, Roma, p. 395-402.

Münzer, Friederich, 1905, s. v. Domitius (43), RE, V, col. 1419-1424.

OAKLeY, Stewart Philipp, 2005, A Commentary on Livy. Books VI-X, Volume III, Book IX, Oxford.

Pallottino, Massimo, 1984, Etruscologia, 7e éd. (1ère éd. 1942), Milano.

Pallottino, Massimo, 1993, Origini e storia primitiva di Roma, Milano.

Palmer, Robert E. A., 1969, The King and the Comitium. A Study of Rome's oldest Public Document, Wiesbaden (Historia Einzelschriften 11).

Palombi, Domenico, 1997, Tra Palatino ed Esquilino: Velia, Carinae, Fagutal. Storia urbana di tre quartieri di Roma antica, Rome (Rivista dell'Istituto Nazionale d'Archeologia e Storia dell'Arte, Supplemento 1).

PAPI, Emanuele, 1995, s. v. Domus Regis sacrorum / sacrificuli, LTUR, II (D-G), p. 169-170.

Pina Polo, Francisco, 1989, Las contiones civiles y militares en Roma, Zaragoza.

Pouthier, Pierre, 1981, Ops et la conception divine de l'abondance dans la religion romaine jusqu'à la mort d'Auguste, Rome (Bibliothèque des Écoles françaises d'Athènes et de Rome 242).

Rodrígez Almeida, Emilio, 1993, s. v. Carinae, LTUR, I (A-C), p. 239-240.

RomanelLI, Pietro, 1955, «Terrecotte architettoniche del Foro Romano », Bollettino d'arte 40, p. 203-207.

RosenberG, Arthur, 1914a, s. v. Rex, RE, I, A 1, col. 703-721.

RosenberG, Arthur, 1914b, s. v. Rex sacrorum, RE, I, A 1, 1914, col. 721-726.

RüPKE, Jörg, 1995, Kalender und Öffentlichkeit. Die Geschichte der Repräsentation und religiösen Qualifikation von Zeit in Rom, Berlin - New York (Religionsgeschichtliche Versuche und Vorarbeiten 40).

RüPKE, Jörg, 2005, Fasti sacerdotum. Die Mitglieder der Priesterschaften und das sakrale Funktionspersonal römischer, griechischer, orientalischer und jüdisch-christlicher Kulte in der Stadt Rom von 300 v. Chr. bis 499 n. Chr., Wiesbaden.

RüPKE, Jörg, 2011, The Roman Calendar from Numa to Constantine. Time, History, and the Fasti (English translation by David M. B. Richardson), Chichester (West Sussex, GB) - Malden (Mass., USA).

RüPKE, Jörg, 2012, « Rationalizing religious practices: the Pontifical Calendar and the Law », dans Olga TellegenCouperus (éd.), Law and Religion in the Roman Republic, Leiden - Boston (Mnemosyne Supplements 336), p. 89-103.

Russo, Federico, 2015, L'odium regni a Roma tra realtà politica e finzione storiografica, Pisa.

RYstedT, Eva, 1993, «Panther followed by lion on the reconstruction of the Regia plaques », dans RYSTEDT \& WIKANDER 1993, p. 249-253.

Rystedt, Eva, Wikander, Charlotte \& Wikander, Örjan (éd.), 1993, Deliciae fictiles. Proceedings of the First International Conference on Central Italic architectural Terracottas at the Swedish Institute in Rome, 10-12 December 1990, Stockholm.

SAntoro, Simona, 2016, Il Cippo del Foro romano. Inquadramento storico-linguistico, Mozzecane (VR).

SCHEID, John, 1984, « Le prêtre et le magistrat. Réflexions sur les sacerdoces et le droit public à la fin de la République », dans Claude Nicolet (éd.), Des ordres à Rome, Paris, p. 243-280.

Scheid, John, 1992, «Le prêtre », dans Andrea Giardina (éd.), L'homme romain [trad. fr. de l'éd. ital. 1989], Paris, p. 97-104. 
SCHEID, John, 1998, La religion des Romains, Paris.

SCHeID, John, 2001, Religion et piété à Rome, $2^{\mathrm{e}}$ éd. (1ère éd. 1985), Paris.

ScodellaRI, Emmanuel, 2004, « L'image de l'altérité dans la décoration de la Regia servienne. Problèmes d'interprétation », dans Yves Perrin \& Thierry Petit (éd.), Iconographie impériale, iconographie royale, iconographie des élites dans le monde gréco-romain, Saint-Étienne (Centre de Recherche en Histoire de l'Université de Saint-Étienne 1), p. 175-192.

Scott, Russell T., 1995, s. v. Domus publica, LTUR, II (D-G), p. 165-166.

Scott, Russell T., 1999a, s. v. Regia, LTUR, IV (P-S), p. 189-192.

Scott, Russell T., 1999b, s. v. Schola: kalatores Pontificum et Flaminum, LTUR, IV (P-S), p. 243-244.

Seguin, Roger, 1988, "Remarques sur les origines des pontifes romains : Pontifex maximus et Rex sacrorum », dans Danielle Porte \& Jean-Pierre Néraudau (éd.), Hommages à Henri Le Bonniec : res sacrae, Bruxelles, p. 405-418.

Sмітн, Christopher John, 1996, Early Rome and Latium. Economy and Society (c. 1000 to 500 BC), Oxford.

Sмгтн, Christopher John, 2011, « Thinking about Kings », Bulletin of the Institute of Classical Studies 54-2, p. 21-42. Staccioli, Romolo A., 1981, « Sulla Regia », Parola del Passato 36, p. 78-79.

Steffens, Franz, 1910, Paléographie latine. 125 Fac-similés en phototypie accompagnés de transcriptions et d'explications avec un exposé systématique de l'histoire de l'écriture latine. Edition française d'après la nouvelle édition allemande par Rémi Coulon, Trèves-Paris.

Stopponi, Simonetta (éd.), 1985, Case e palazzi d'Etruria, Milano.

Stouder, Ghislaine, 2011, La diplomatie romaine : histoire et représentations (396-264 avant J. -C.), thèse de Doctorat, Université d'Aix-Marseille.

Stroux, Johannes, 1931, « Die Foruminschrift beim Lapis niger », Philologus 86, p. 460-491.

SzemLeR, George John, 1978, « Pontifex», RE, Suppl. XV, col. 331-396.

Suerbaum, Werner (éd.), 2014, Nouvelle histoire de la littérature latine, I, La littérature de l'époque archaïque, des origines à la mort de Sylla. La période prélittéraire et l'époque de 240 à 78 av. J. -C. (version française de l'éd. allemande de 2002, sous la direction de Gérard Freyburger \& François Heim), Turnhout.

Torelli, Mario, 1981, Storia degli Etruschi, Roma - Bari.

ToRelli, Mario, 1993, «Regiae d'Etruria e del Lazio e immaginario figurato del potere », dans Russell T. Scott \& Ann Reynolds Scott (éd.), Eius virtutis studiosi: classical and postclassical studies in memory of Frank Edward Brown (19081988), Washington (DC), p. 85-121.

ToRelli, Mario, 1997, Il rango, il rito, l'immagine. Alle origini della rappresentazione storica romana, Milano.

Van Haeperen, Françoise, 2002, Le collège pontifical (3e s. a.C. - $4^{e}$ s. p.C.). Contribution à l'étude de la religion publique romaine, Bruxelles - Rome.

VANotrI, Gabriella, 1999, «Roma polis Hellenis, Roma polis Tyrrhenis. Riflessioni sul tema », MEFRA 111-1, p. 217-255.

Verzár, Monica, 1980, « Pyrgi e l'Afrodite di Cipro. Considerazioni sul programma decorativo del tempio B », MEFRA 92-1, p. 35-86.

WACHTER, Rudolf, 1987, Altlateinische Inschriften. Sprachliche und epigraphische Untersuchungen zu den Dokumenten bis etwa 150 v. Chr., Bern - Frankfurt/Main - New York - Paris.

Wolf, Joseph Georg, 1980, «Die literarische Überlieferung der Publikation der Fasten und Legisaktionen durch Gnaeus Flavius », Nachrichten der Akademie der Wissenschaften in Göttingen (Philologisch-historische Klasse), 2, p. 11-29. 